Atmos. Chem. Phys., 13, 8019-8043, 2013

www.atmos-chem-phys.net/13/8019/2013/

doi:10.5194/acp-13-8019-2013

(c) Author(s) 2013. CC Attribution 3.0 License.

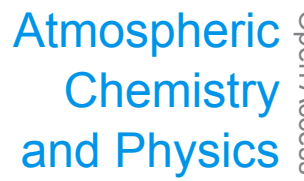

\title{
Secondary organic aerosol formation from biomass burning intermediates: phenol and methoxyphenols
}

\author{
L. D. Yee ${ }^{1, *}$, K. E. Kautzman ${ }^{2, * *}$, C. L. Loza ${ }^{2}$, K. A. Schilling ${ }^{2}$, M. M. Coggon ${ }^{2}$, P. S. Chhabra ${ }^{2, * * *}$, M. N. Chan ${ }^{1, * * * *}$, \\ A. W. H. Chan ${ }^{2, * * * *}$, S. P. Hersey ${ }^{1}$, J. D. Crounse ${ }^{3}$, P. O. Wennberg ${ }^{1,3}$, R. C. Flagan ${ }^{2,1}$, and J. H. Seinfeld ${ }^{2,1}$ \\ ${ }^{1}$ Division of Engineering and Applied Science, California Institute of Technology, Pasadena, CA, USA \\ ${ }^{2}$ Division of Chemistry and Chemical Engineering, California Institute of Technology, Pasadena, CA, USA \\ ${ }^{3}$ Division of Geological and Planetary Sciences, California Institute of Technology, Pasadena, CA, USA \\ * now at: Department of Environmental Science, Policy and Management, University of California, Berkeley, USA \\ ** now at: Department of Chemistry, Towson University, Towson, MD, USA \\ *** now at: Aerodyne Research Inc., Billerica MA, USA \\ **** now at: Chemical Sciences Division, Lawrence Berkeley National Laboratory, Berkeley, CA, USA \\ ***** now at: Department of Chemical Engineering and Applied Chemistry, University of Toronto, Toronto, Canada
}

Correspondence to: J. H. Seinfeld (seinfeld@caltech.edu)

Received: 20 January 2013 - Published in Atmos. Chem. Phys. Discuss.: 6 February 2013

Revised: 13 June 2013 - Accepted: 20 June 2013 - Published: 21 August 2013

\begin{abstract}
The formation of secondary organic aerosol from oxidation of phenol, guaiacol (2-methoxyphenol), and syringol (2,6-dimethoxyphenol), major components of biomass burning, is described. Photooxidation experiments were conducted in the Caltech laboratory chambers under low- $\mathrm{NO}_{\mathrm{x}}$ ( $<10 \mathrm{ppb}$ ) conditions using $\mathrm{H}_{2} \mathrm{O}_{2}$ as the $\mathrm{OH}$ source. Secondary organic aerosol (SOA) yields (ratio of mass of SOA formed to mass of primary organic reacted) greater than $25 \%$ are observed. Aerosol growth is rapid and linear with the primary organic conversion, consistent with the formation of essentially non-volatile products. Gas- and aerosol-phase oxidation products from the guaiacol system provide insight into the chemical mechanisms responsible for SOA formation. Syringol SOA yields are lower than those of phenol and guaiacol, likely due to novel methoxy group chemistry that leads to early fragmentation in the gas-phase photooxidation. Atomic oxygen to carbon $(\mathrm{O}: \mathrm{C})$ ratios calculated from high-resolution-time-of-flight Aerodyne Aerosol Mass Spectrometer (HR-ToF-AMS) measurements of the SOA in all three systems are $\sim 0.9$, which represent among the highest such ratios achieved in laboratory chamber experiments and are similar to that of aged atmospheric organic aerosol. The global contribution of SOA from intermediate volatility and semivolatile organic compounds has been shown to be substantial (Pye and Seinfeld, 2010). An approach to rep-
\end{abstract}

resenting SOA formation from biomass burning emissions in atmospheric models could involve one or more surrogate species for which aerosol formation under well-controlled conditions has been quantified. The present work provides data for such an approach.

\section{Introduction}

Biomass burning is a major source of atmospheric organic aerosol (OA), with contributions from both anthropogenic (biofuel, deforestation, etc.) as well as natural sources such as wildfires. Aerosol produced from biomass burning has been estimated to account for $90 \%$ of all primary organic carbon emitted globally from combustion sources (Ito and Penner, 2005). Bond et al. (2004) estimated global annual emissions of carbonaceous aerosol due to combustion as $8.0 \mathrm{Tg}$ for black carbon (BC) and 33.9 Tg organic carbon (OC). Biofuel and open burning were estimated by these authors to account, respectively, for $20 \%$ and $42 \%$ of $\mathrm{BC}$, and $19 \%$ and $74 \%$, of OC. The amount and composition of organic aerosol formed from these sources vary widely based on combustion conditions and fuel type. Measured wood smoke emissions from fireplaces, for example, depend strongly on the type of fuel consumed and can vary in magnitude by a factor of five for

Published by Copernicus Publications on behalf of the European Geosciences Union. 
Table 1. Chemical properties.

\begin{tabular}{|c|c|c|c|c|}
\hline Compound & Structure & $\begin{array}{l}\text { Boiling Pt. }{ }^{\mathrm{a}} \\
\quad\left({ }^{\circ} \mathrm{C}\right)\end{array}$ & $\begin{array}{l}\text { V.P. }{ }^{\mathrm{a}} @ 25^{\circ} \mathrm{C} \\
(\mathrm{mm} \mathrm{Hg})\end{array}$ & $\begin{array}{c}k_{\mathrm{OH}} \times 10^{11} \\
\left(\operatorname{molec~} \mathrm{cm}^{-3} \mathrm{~s}^{-1}\right)\end{array}$ \\
\hline Phenol & & 182 & 0.351 & $2.7 \pm 0.25$ at $25^{\circ} \mathrm{C}($ Calvert et al., 2002) \\
\hline Guaiacol & & 205 & 0.13 & $7.53 \pm 0.41$ at $21 \pm 2{ }^{\circ} \mathrm{C}$ (Coeur-Tourneur et al., 2010) \\
\hline Syringol & & 261 & $0.00602^{b}$ & $9.66 \pm 1.11$ at $21 \pm 2{ }^{\circ} \mathrm{C}$ (Lauraguais et al., 2012) \\
\hline
\end{tabular}

different fuel sources and sampling techniques (Fine et al., 2001). Particulate matter from biomass burning, including wildfires, residential wood burning, and deforestation is also of major concern for visibility, climate change and health effects (Naeher et al., 2007).

Recent studies have been devoted to measuring and chemically characterizing the gas and particle-phase emissions from biomass burning in-situ (Iinuma et al., 2010; Akagi et al., 2012) and in the laboratory (Veres et al., 2010; Iinuma et al., 2010). Understanding the fate of such emissions in the atmosphere as a plume rises and advects away from the source is a challenge to discern. One approach towards addressing this problem is to simulate the photooxidation of known biomass burning tracers in the laboratory under highly-controlled chemical conditions.

Phenols are produced from the pryolysis of lignin, the second most abundant polymer on Earth comprising the secondary cell wall of plants. Hawthorne et al. (1989) showed that phenols and methoxyphenols account for a significant fraction of particulate matter derived from wood smoke, constituting $21 \%$ and $45 \%$ by mass of total aerosol, respectively. Emission rates for methoxyphenol species from biomass burning have been estimated to range from $420-900 \mathrm{mg} \mathrm{kg}^{-1}$ fuel (Hawthorne et al., 1989; Hawthorne et al., 1992; Schauer et al., 2001). In addition to the significant emission factors of these compounds, guaiacol, which is emitted from both hard and soft wood combustion, and syringol, which is emitted primarily from soft woods, have been proposed as aerosol markers for wood combustion as well as biomarkers to determine human exposure levels (Dills et al., 2001; Simpson and Naeher, 2010).

Such phenolic compounds are used in ozonolysis and photooxidation studies to simulate the chemical fate and aerosol forming potential of such biomass burning intermediates in the atmosphere. Often these include candidate compounds such as phenol and catechol (Atkinson et al., 1992; Olariu, 2001; Olariu et al., 2002; Berndt and Boge, 2003; Tomas et al., 2003; Coeur-Tourneur et al., 2009; Iinuma et al., 2010; Nakao et al., 2011; Ofner et al., 2011). Many of these com- pounds can also serve as model systems for understanding aerosol formation from humic substances, the role of water, and associated heterogenous processes (Ammann et al., 2005; Nieto-Gligorovski et al., 2008; Ofner et al., 2010, 2011; Sun et al., 2010).

Still, little is known about the detailed gas-phase photooxidation mechanism of methoxyphenol compounds. Here we investigate the aerosol-forming potential of phenol and two of the most abundant methoxyphenol species, guaiacol and syringol (Table 1). Both guaiacol and phenol are intermediate volatility organic compounds; syringol has a vapor pressure 100 times less than those of phenol and guaiacol. The molecular structures are shown in Table 1 along with vapor pressures and reaction rate constants with $\mathrm{OH}$.

We determine the fractional yield of secondary organic aerosol (SOA) from photooxidation of phenol, guaiacol, and syringol by $\mathrm{OH}$ in laboratory chamber studies under low$\mathrm{NO}_{\mathrm{x}}\left(\left[\mathrm{NO}_{\mathrm{x}}\right]_{0}<10 \mathrm{ppb}\right)$ conditions. While $\mathrm{NO}_{\mathrm{x}}$ is certainly present in biomass burning events at higher levels than this, we focus on the results of the low- $\mathrm{NO}_{\mathrm{x}}$ experiments in the main text and leave discussion on the effect of $\mathrm{NO}_{\mathrm{x}}$ in the Appendix. The atmospheric chamber experiments performed on these systems were performed under idealized chemical conditions such that specific regimes of chemistry could be isolated. That is, low- $\mathrm{NO}_{\mathrm{x}}$ experiments resulted in the predominant fate of $\mathrm{RO}_{2}$ radical to be reaction with $\mathrm{HO}_{2}$, and in the high- $\mathrm{NO}_{\mathrm{x}}$ experiments, reaction with $\mathrm{NO}_{\mathrm{x}}$. In the atmosphere there exists a spectrum of chemical regimes that depend on proximity to the heart of the biomass burning source. Owing to the high- $\mathrm{NO}_{\mathrm{x}}$ experiments resulting in levels of total $\mathrm{NO}_{\mathrm{x}}$ approaching $1 \mathrm{ppm}$ (beyond typical atmospheric levels), we find the results to be chemically instructive, though not practical for use as an accurate representation of the SOA formation from these systems under atmospherically relevant $\mathrm{NO}_{\mathrm{x}}$ conditions. For example, Iinuma et al. (2010) measured co-located $\mathrm{NO}_{\mathrm{x}}$ to be on the order of $20 \mathrm{ppb}$.

Studies on the photooxidation mechanisms of aromatics and phenol in general find that the product distributions for aromatics chemistry are qualitatively similar in the absence 
Table 2. Experimental conditions and aerosol yields.

\begin{tabular}{|c|c|c|c|c|c|c|c|c|c|}
\hline $\begin{array}{l}\text { Date } \\
(2010)\end{array}$ & Organic & $\begin{array}{c}{[\mathrm{Org}]_{0}} \\
(\mathrm{ppb})\end{array}$ & $\begin{array}{c}{[\mathrm{Org}]_{\mathrm{f}}} \\
(\mathrm{ppb})\end{array}$ & $\begin{array}{l}\mathrm{RH}_{0} \\
(\%)\end{array}$ & $\begin{array}{c}{\left[\mathrm{NO}_{2}\right]_{0}} \\
(\mathrm{ppb})\end{array}$ & $\begin{array}{c}{[\mathrm{NO}]_{0}} \\
(\mathrm{ppb})\end{array}$ & $\begin{array}{c}\mathrm{Vol}_{0} \mathrm{e}^{3} \\
\mu \mathrm{m}^{3} \mathrm{~cm}^{-3}\end{array}$ & $\begin{array}{c}\operatorname{Vol}_{\mathrm{f}}{ }^{\mathrm{e}} \\
\mu \mathrm{m}^{3} \mathrm{~cm}^{-3}\end{array}$ & Yield \\
\hline $1 / 29$ & guaiacol & 66.3 & 13.4 & 5.6 & $<\mathrm{LDL}^{\mathrm{d}}$ & $<\mathrm{LDL}^{\mathrm{d}}$ & 18.2 & 120.0 & $0.49 \pm 0.01$ \\
\hline $2 / 2$ & guaiacol & 5.9 & $<\mathrm{LDL}^{\mathrm{a}}$ & 5.8 & $<\mathrm{LDL}^{\mathrm{d}}$ & $<\mathrm{LDL}^{\mathrm{d}}$ & 16.4 & 25.0 & $0.46 \pm 0.03$ \\
\hline $2 / 4$ & guaiacol & 12.4 & $<\mathrm{LDL}^{\mathrm{a}}$ & 5.5 & $<\mathrm{LDL}^{\mathrm{d}}$ & $<\mathrm{LDL}^{\mathrm{d}}$ & 13.6 & 31.0 & $0.44 \pm 0.03$ \\
\hline $2 / 6$ & guaiacol & 45.5 & 4.1 & 6.7 & $<\mathrm{LDL}^{\mathrm{d}}$ & 5 & 12.9 & 85.0 & $0.50 \pm 0.02$ \\
\hline $2 / 11$ & phenol & 47.6 & 9.9 & 5.7 & $<\mathrm{LDL}^{\mathrm{d}}$ & 6 & 16.0 & 58.0 & $0.44 \pm 0.08$ \\
\hline $2 / 15$ & phenol & 10.0 & 2.1 & 6.2 & $<\mathrm{LDL}^{\mathrm{d}}$ & 5 & 11.4 & 20.0 & $0.40 \pm 0.06$ \\
\hline $2 / 17$ & phenol & 73.9 & 14.4 & $<\mathrm{LDL}^{\mathrm{c}}$ & $<\mathrm{LDL}^{\mathrm{d}}$ & $<\mathrm{LDL}^{\mathrm{d}}$ & 12.0 & 32.9 & $0.25 \pm 0.01$ \\
\hline $2 / 20$ & phenol & 101.9 & 18.8 & $<\mathrm{LDL}^{\mathrm{c}}$ & $<\mathrm{LDL}^{\mathrm{d}}$ & 5 & 10.0 & 69.0 & $0.24 \pm 0.03$ \\
\hline $3 / 10$ & syringol & 185.1 & $<\mathrm{LDL}^{\mathrm{b}}$ & $<\mathrm{LDL}^{\mathrm{c}}$ & 7 & $<\mathrm{LDL}^{\mathrm{d}}$ & 11.0 & 325.0 & $0.37 \pm 0.01$ \\
\hline $3 / 15$ & syringol & 49.5 & $<\mathrm{LDL}^{\mathrm{b}}$ & $<\mathrm{LDL}^{\mathrm{c}}$ & $<\mathrm{LDL}^{\mathrm{d}}$ & $<\mathrm{LDL}^{\mathrm{d}}$ & 14.2 & 67.0 & $0.25 \pm 0.01$ \\
\hline $3 / 29$ & syringol & 112.9 & $<\mathrm{LDL}^{\mathrm{b}}$ & $<\mathrm{LDL}^{\mathrm{c}}$ & 9 & $<\mathrm{LDL}^{\mathrm{d}}$ & 11.7 & 174.0 & $0.34 \pm 0.01$ \\
\hline
\end{tabular}

${ }^{a}$ below CIMS lower detection limit (LDL) of $0.1 \mathrm{ppb}$ for guaiacol

${ }^{\mathrm{b}}$ CIMS LDL $=0.5 \mathrm{ppb}$ for syringol

${ }^{\mathrm{c}} \mathrm{RH}$ probe $\mathrm{LDL}=5 \% \mathrm{RH}$

${ }^{\mathrm{d}} \mathrm{NO}_{\mathrm{x}}$ Analyzer LDL $=5 \mathrm{ppb}$

e $\mathrm{Vol}_{0}$ is initial seed volume; $\mathrm{Vol}_{\mathrm{f}}$ is final volume (seed + organic aerosol), as measured by DMA

and presence of $\mathrm{NO}_{\mathrm{x}}$ (Atkinson et al., 1992; Olariu et al., 2002; Sato et al., 2007), with noted presence of nitroaromatics generated in the presence of $\mathrm{NO}_{\mathrm{x}}$. Still, these products tend to have gas-phase yields less than 0.1 (Olariu et al., 2002; Berndt and Boge, 2006). Thus, the low- $\mathrm{NO}_{\mathrm{x}}$ data presented here focus analyses on relevant gas- and particlephase constituents in guaiacol photooxidation to elucidate the chemical mechanism involved in guaiacol SOA formation. This chemistry may best represent the chemical regime in which biomass burning emissions are transported to areas where $\mathrm{NO}_{\mathrm{x}}$ levels have become diluted and photochemistry ensues. We also qualitatively compare the chemistry of the tested compounds to explore why syringol results in lower SOA yield compared to phenol and guaiacol. Further motivation for this work is the potential use of phenol, guaiacol, and syringol as compounds to represent biomass burning emissions in atmospheric models of organic aerosol formation. SOA products identified in the laboratory studies may also serve as markers for biomass burning in ambient aerosols.

\section{Experimental section}

\subsection{Chamber experiments}

All experiments were carried out in the Caltech dual $28 \mathrm{~m}^{3}$ Teflon chambers. Details of the facilities have been described previously (Cocker et al., 2001; Keywood et al., 2004). Before each experiment, the chambers were flushed with dried purified air $\mathrm{RH}<5 \%, \mathrm{NO}_{\mathrm{x}}<2 \mathrm{ppb}$ ) for $>24 \mathrm{~h}$, until the particle number concentration was $<100 \mathrm{~cm}^{-3}$ and the volume concentration was $<0.1 \mu \mathrm{m}^{3} \mathrm{~cm}^{-3}$. In all yield experiments, ammonium sulfate seed aerosol was used to promote conden- sation of low volatility oxidation products. The seed aerosol was generated by atomization of a $0.015 \mathrm{M}$ aqueous ammonium sulfate solution. Following atomization, the size distribution of the seed particles peaked at $\sim 56 \mathrm{~nm}$ with an average number concentration of $\sim 2700 \mathrm{~cm}^{-3}$, and a total seed volume concentration of $10-15 \mu \mathrm{m}^{3} \mathrm{~cm}^{-3}$ was achieved. The hydrocarbon was introduced into the chamber by injecting a known volume of pure hydrocarbon into a glass bulb and flowing purified air over the hydrocarbon at $5 \mathrm{~L} \mathrm{~min}^{-1}$ until the hydrocarbon had fully vaporized. Gentle heat was applied to the glass bulb to support evaporation of syringol (solid) into the chamber.

For these low- $\mathrm{NO}_{\mathrm{x}}$ experiments, hydrogen peroxide $\left(\mathrm{H}_{2} \mathrm{O}_{2}\right)$ was used as the $\mathrm{OH}$ precursor. We refer to the reaction conditions of these experiments as "low- $\mathrm{NO}_{\mathrm{x}}$ " because there is no intentional injection of $\mathrm{NO}_{\mathrm{x}}\left(\left[\mathrm{NO}_{\mathrm{x}}\right]_{0}<5 \mathrm{ppb}\right.$, the lower detection limit of the $\mathrm{NO}_{\mathrm{x}}$ analyzer). There are three hundred $40 \mathrm{~W}$ black lights, Sylvania 350BL, with an emission spectrum that peaks at $340-350 \mathrm{~nm}$ wavelength. Based on the irradiance spectrum of the lights and the absorption cross section of $\mathrm{H}_{2} \mathrm{O}_{2}$ (Sander, 2011), this results in a photolysis rate constant, $j_{\mathrm{H}_{2} \mathrm{O}_{2}}=2.9 \times 10^{6} \mathrm{~s}^{-1}$. Prior to atomization of the ammonium sulfate seed, $\mathrm{H}_{2} \mathrm{O}_{2}$ was introduced by flowing $5 \mathrm{~L} \mathrm{~min}^{-1}$ of purified air through a glass trap containing $280 \mu \mathrm{L}$ of a $50 \%$ aqueous $\mathrm{H}_{2} \mathrm{O}_{2}$ solution. The glass trap was submerged in a warm water bath maintained at $35-38^{\circ} \mathrm{C}$. This resulted in an approximate concentration of 4 ppm $\mathrm{H}_{2} \mathrm{O}_{2}$ in the chamber.

The aerosol number concentration and size distribution were measured by a differential mobility analyzer (DMA, TSI model 3081) coupled with a condensation nuclei counter (TSI, CNC-3760). After allowing all concentrations to 
stabilize, irradiation was initiated. The temperature $(T)$, relative humidity $(\mathrm{RH})$, and concentrations of $\mathrm{O}_{3}, \mathrm{NO}$, and $\mathrm{NO}_{\mathrm{x}}$ were continuously monitored. Experiments were run at temperatures ranging $20-26^{\circ} \mathrm{C}$ and varied within $\pm 2{ }^{\circ} \mathrm{C}$. $\mathrm{RH}$ remained below $10 \%$. The lower detection limits (LDL) of the utilized analyzers are $5 \% \mathrm{RH}, 2 \mathrm{ppb} \mathrm{O}_{3}$, and $5 \mathrm{ppb} \mathrm{NO}_{\mathrm{x}}$. Table 2 summarizes the experimental conditions for the series of methoxyphenol oxidation experiments conducted.

\subsection{Gas-phase measurements}

\subsubsection{Gas Chromatography/Flame-Ionization Detection (GC/FID)}

The hydrocarbon concentration was continuously monitored by GC/FID in the phenol experiments. Chamber air was sampled into a $10 \mathrm{~mL}$ injection loop and injected onto a HP5 $15 \mathrm{~m} \times 0.53 \mathrm{~mm} \mathrm{ID} \times 1 \mu \mathrm{m}$ thickness column installed on a 6890 Agilent GC. The GC response was calibrated by dissolving a known mass of the hydrocarbon in methanol and then vaporizing a known volume of that solution into a $55 \mathrm{~L}$ Teflon chamber. Guaiacol and syringol measurements obtained using the GC/FID were unreliable due to condensation loss in the sample loop; thus, the hydrocarbon concentration during these experiments was monitored using Chemical Ionization Mass Spectrometry (CIMS) in negative mode operation. The LDL for phenol on the GC-FID was determined to be $\sim 1 \mathrm{ppb}$ from calibrations.

\subsubsection{Chemical Ionization Mass Spectrometry (CIMS)}

Monitoring of gas-phase oxidation products was carried out in real time by the use of a CIMS instrument. The details of this instrument are described elsewhere (St. Clair et al., 2010). The instrument operates in both negative mode, using $\mathrm{CF}_{3} \mathrm{O}^{-}$as a reagent ion, and in positive proton transfer reaction (PTR)-MS mode. Negative mode is found to be more selective towards the detection of hydroperoxides and polar molecules, particularly acids, while positive mode detects a broader range of organic compounds. Analytes in negative mode can be monitored as the cluster product $\left[\mathrm{R} \cdot \mathrm{CF}_{3} \mathrm{O}\right]^{-}$ and/or as the transfer product if it is more strongly acidic $[\mathrm{R} \cdot \mathrm{F}]^{-}$, where $\mathrm{R}$ is the analyte. Analytes in positive mode cluster as $\left[\mathrm{R} \cdot\left(\mathrm{H}_{2} \mathrm{O}\right)_{n}\right]^{+}$. Mass scans covering masses 50 $300 \mathrm{amu}$ for negative mode, and 50-200 amu for positive mode, with a total scan time of $\sim 6$ min were continuously repeated over the course of each experiment.

Guaiacol was monitored at the fluoride transfer product $\left([\mathrm{M}+19]^{-}\right), m / z, 143$, and the cluster product $\left([\mathrm{M}+85]^{-}\right)$, $\mathrm{m} / \mathrm{z} 209$, in negative mode operation. Syringol was also monitored at the fluoride transfer product, $\mathrm{m} / z, 173$, and the cluster product, $m / z 239$. Calibrations of guaiacol and syringol on the CIMS were performed similar to those of phenol on the GC-FID by preparing $55 \mathrm{~L}$ Teflon chamber standards of varying concentrations of the methoxyphenol compounds. The
LDL for guaiacol on the CIMS was established to be $100 \mathrm{ppt}$ and that for syringol to be $500 \mathrm{ppt}$. While phenol was detected at both the transfer $(\mathrm{m} / \mathrm{z}, 113)$ and the cluster product $(\mathrm{m} / \mathrm{z}, 179)$, a calibration curve was not made because a photooxidation product in the phenol system interfered significantly at $m / z 113$.

\subsection{Particle-phase measurements}

\subsubsection{Chamber filter sample collection, extraction, and off-line chemical characterization}

A detailed description of the aerosol filter sample collection and extraction protocol for the Caltech laboratory chambers has been previously published (Surratt et al., 2008). Aerosol samples were collected on Teflon filters (PALL Life Sciences, $47 \mathrm{~mm}$ diameter, $1.0 \mu \mathrm{m}$ pore size, teflomembrane). Filter samplers employed for aerosol filter sample collection used a front and back-up filter sampling approach, in which back-up filters were collected in order to examine if aerosol breakthrough from the front filter occurred or whether evaporation of semivolatiles from the front filter occurred during sampling. In all experiments, no SOA constituents were detected on the back-up filters. Filter sampling was initiated when the aerosol volume reached its maximum (constant) value, as determined by the DMA. Lights were turned off after the filter sampling period was complete. Depending on the total volume concentration of aerosol in the chamber, the duration of filter sampling was $1.8-2.1 \mathrm{~h}$, which resulted in 2.0$2.9 \mathrm{~m}^{3}$ of total chamber air sampled. Teflon filter extraction protocols in high-purity methanol (LC-MS CHROMASOLVGrade, Sigma-Aldrich) have been described previously (Surratt et al., 2008). The resultant filter extracts were then analyzed by a Waters ACQUITY ultra performance liquid chromatography (UPLC) system, coupled with a Waters LCT Premier TOF mass spectrometer equipped with an ESI source, allowing for accurate mass measurements by UPLC/ESI-TOFMS to be obtained for each ion (Surratt et al., 2008).

Selected filter extracts from experiments were also analyzed by a Thermo Finnigan Surveyor high performance liquid chromatography (HPLC) system (pump and autosampler) coupled to a Thermo Finnigan LCQ ion trap mass spectrometer (ITMS) equipped with an ESI source, allowing for tandem MS measurements to be obtained. Data were acquired and processed using Xcalibur version 1.3 software. A Waters Atlantis T3 column $(3 \mu \mathrm{m}$ particle size; $2.1 \times 150 \mathrm{~mm}$ ) was employed, which is similar to the Water ACQUITY UPLC HSS column used for the UPLC/ESITOFMS analysis. The mobile phases consisted of $0.1 \%$ acetic acid in water (A) and $0.1 \%$ acetic acid in methanol (B). The applied $45 \mathrm{~min}$ gradient elution program was as follows: the concentration of eluent B was kept at $3 \%$ for $4 \mathrm{~min}$, then increased to $100 \%$ in $21 \mathrm{~min}$, holding at $100 \%$ for $10 \mathrm{~min}$, then decreased to $3 \%$ in $5 \mathrm{~min}$, and kept at $3 \%$ 
for $5 \mathrm{~min}$. The injection volume and flow rate were $10 \mu \mathrm{L}$ and $0.2 \mathrm{~mL} \mathrm{~min}^{-1}$, respectively. The ion trap mass analyzer was operated under the following conditions: sheath gas flow $\left(\mathrm{N}_{2}\right), 65$ arbitrary units; auxiliary gas flow $\left(\mathrm{N}_{2}\right), 3$ arbitrary units; source voltage, $-4.5 \mathrm{kV}$; capillary voltage, $-14.5 \mathrm{~V}$; tube lens offset, $7 \mathrm{~V}$; capillary temperature, $200^{\circ} \mathrm{C}$; and maximum ion injection time, $200 \mathrm{~ms}$. Two scan events were used during each chromatographic run; scan event 1 was the full scan mode in which data were collected from $\mathrm{m} / \mathrm{z}, 120$ to 600 in the negative ionization mode and scan event 2 was the MS2 mode in which product ions were generated from significant base peak ions observed in scan event 1. For MS2 experiments, an isolation width of $2.5 \mathrm{~m} / \mathrm{z}$ units and a normalized collision energy level of $35 \%$ were applied. The [M$\mathrm{H}]^{-}$ion signal optimization was carried out by introducing a $1 \mathrm{mg} \mathrm{mL}^{-1}$ malic acid standard solution. Due to the onaxis ESI source that is characteristic of the LCQ ITMS instrument, a solvent delay time of $3.5 \mathrm{~min}$ (which diverted the column effluent from the ESI source to waste) was employed to prevent clogging by nonvolatile salts at the entrance of the capillary.

\subsubsection{High-Resolution Time-of-Flight Aerosol Mass Spectrometry (HR-ToF-AMS)}

Real-time aerosol mass spectra were obtained using an Aerodyne HR-ToF-AMS (DeCarlo et al., 2006). The HR-ToFAMS was operated in a lower resolution, higher sensitivity "V-mode", and a high-resolution "W" mode, switching between modes once every minute. The "V-mode" data were analyzed to extract sulfate, ammonium, and organic spectra according to procedures in Allan et al. (2004). Calculation of the SOA densities were achieved by comparing the particle mass distributions obtained using the particle ToF mode and the volume distributions obtained by the DMA (Bahreini et al., 2005) in nucleation (seed-free) experiments. $\mathrm{O}: \mathrm{C}, \mathrm{N}: \mathrm{C}$, and $\mathrm{H}: \mathrm{C}$ ratios were determined from "W" mode data using the APES toolbox and applying the procedures outlined in Aiken et al. (2007) and Aiken et al. (2008). The particle-phase signal of $\mathrm{CO}^{+}$and the organic contribution to $\mathrm{H}_{\mathrm{x}} \mathrm{O}^{+}$ions were estimated as described in Aiken et al. (2008).

Particle-into-Liquid Sampler/Ion Chromatography (PILS/ IC) was also employed as described in Kautzman et al. (2010) for the guaiacol experiments, though we find that $<\mathrm{C}_{6}$ diacids do not constitute an important fraction of the SOA formed.

\section{SOA yields}

The formation of secondary organic aerosol (SOA) results from the gas-particle partitioning of low-vapor-pressure products formed in the oxidation of volatile organic compounds (VOCs). The SOA yield is defined as the ratio of mass of organic aerosol formed, $\Delta \mathrm{M}_{\mathrm{o}}$, to the mass of the parent organic species consumed, $\Delta \operatorname{Org}, Y=\Delta \mathrm{M}_{\mathrm{o}} / \Delta \operatorname{Org}$. The SOA yields for all experiments are summarized in Table 2. To calculate the mass concentration of the SOA, the SOA volumes established by DMA measurements are wall-loss corrected following procedures in Keywood et al. (2004); $\mathrm{Ng}$ et al. (2007) and then multiplied by the SOA density, as determined by the AMS in seed-free (nucleation) experiments. A density of $1.65 \mu \mathrm{g} \mathrm{cm}^{-3}$ was determined for phenol. Guaiacol and syringol densities were determined to be 1.45 and $1.49 \mu \mathrm{g} \mathrm{cm}^{-3}$, respectively. The $\mathrm{O}: \mathrm{C}$ was calculated at time of maximum SOA growth for these systems and were reported in Chhabra et al. (2011). O : C values of $0.88 \pm 0.27$, $0.89 \pm 0.28$, and $0.97 \pm 0.30$ were calculated for the phenol, guaiacol, and syringol systems, respectively.

Aerosol yields as a function of organic mass for the studied systems are shown in Fig. 1. Phenol traces are denoted by square markers and are of a green shade. Guaiacol traces are denoted by circles and are of a blue shade. Triangle markers indicate the syringol experiments and are colored in various shades of purple. The error bars represent the propagated uncertainty from all parameters varying with time for each experiment. Generally, there is larger error associated with yield measurements at smaller $\mathrm{M}_{\mathrm{o}}$. Within a system, the yield curves generally converge within uncertainty for $M_{0}>20 \mu \mathrm{g} \mathrm{cm}^{-3}$ and there is greater deviation for experiments with the least amount of hydrocarbon reacted within a set of loadings tested for. This may indicate the existence of chemical differences as well as equilibrium and kinetic regimes of aerosol growth that are affected by initial hydrocarbon loading.

About $80 \%$ of the initial phenol was reacted in these experiments. Final SOA yields for phenol range $24-44 \%$ under the experimental conditions (Fig. 1a). For phenol, the hydrocarbon measurement obtained from all gas-phase instruments displayed interferences under low- $\mathrm{NO}_{\mathrm{x}}$ conditions, leading to a wider spread and greater uncertainty in the yield curve parameters. Still, the measured yields under low- $\mathrm{NO}_{\mathrm{x}}$ conditions overlap with the range of $38-45 \%$ reported by Nakao et al. (2011). Greater than $90 \%$ of the initial guaiacol was consumed over the course of all experiments except for the higher guaiacol loading 1/29 experiment as noted in Table 2. SOA yields from guaiacol photooxidation, based on the final aerosol volume achieved, range $44-50 \%$ (Fig. 1b). Within six hours of irradiation, the syringol levels are lower than the limit of detection and SOA yields of $25-37 \%$ result (Fig. 1c). This range overlaps yields of 10-36\% reported for syringol photooxidation under high- $\mathrm{NO}_{\mathrm{x}}$ (approaching $10 \mathrm{ppm}$ NO) conducted by Lauraguais et al. (2012) using $\mathrm{CH}_{3} \mathrm{ONO}$ as the $\mathrm{OH}$ source.

Figure 1d compares phenol, guaiacol, and syringol experiments in which approximately $300 \mu \mathrm{g} \mathrm{cm}^{-3}$ of hydrocarbon precursor reacted. Phenol and guaiacol follow a similar trend and syringol aerosol is the only system that plateaus with increasing organic aerosol mass, resulting in aerosol 

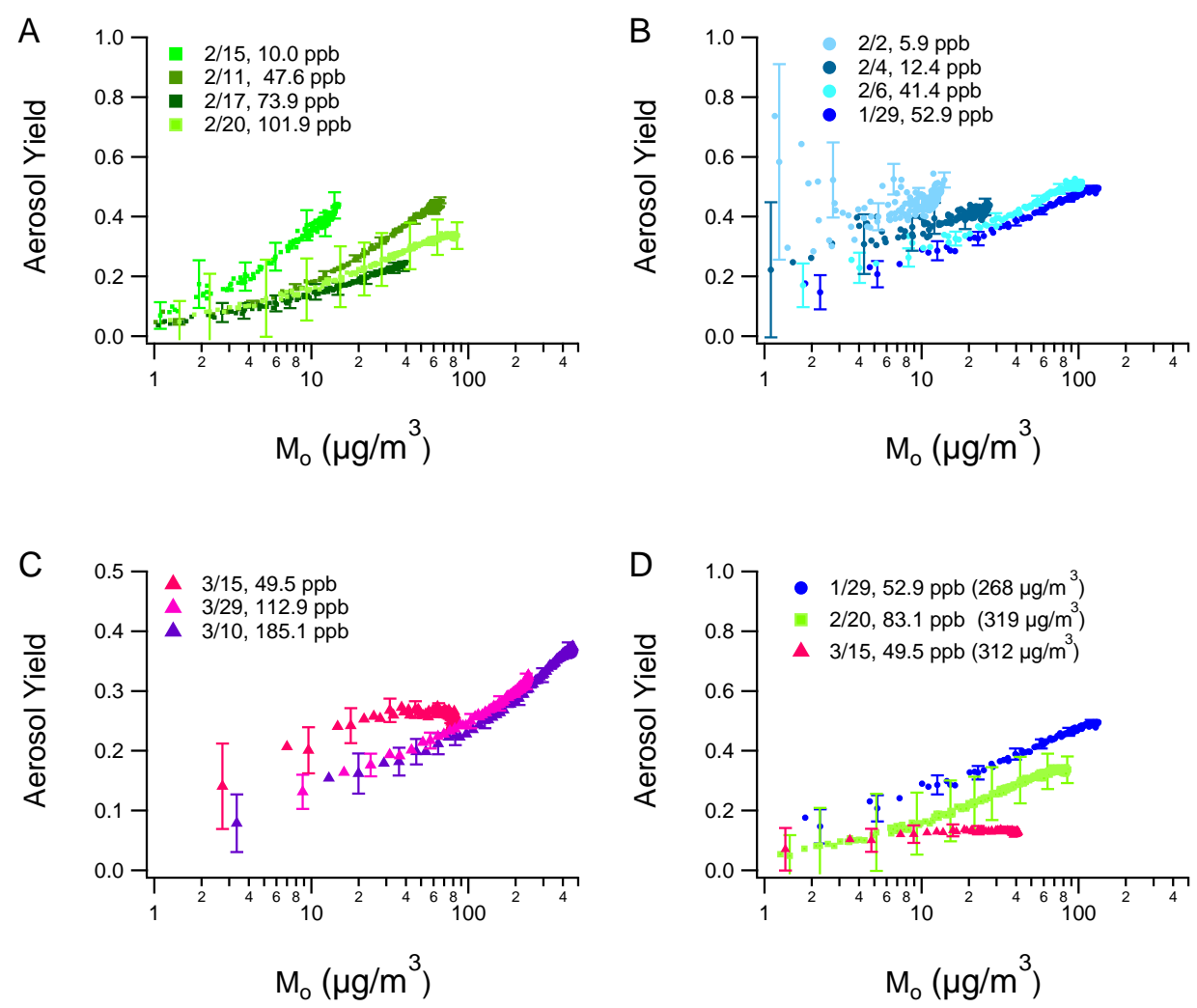

Fig. 1. Aerosol yields as a function of organic aerosol mass for (A) phenol (squares), (B) guaiacol (circles), and (C) syringol (triangles). (D) Comparison across systems for similar amounts of reacted hydrocarbon by mass concentration.

yields that are lower than those of phenol and guaiacol at $\mathrm{M}_{\mathrm{o}}>20 \mu \mathrm{g} \mathrm{cm}{ }^{-3}$.

One might expect that the relatively higher boiling point and lower vapor pressure of syringol might suggest enhanced ability of it or its photooxidation products to partition to the particle-phase, as vapor pressure is a key component in calculating the partitioning coefficient (Pankow, 1994). Syringol vapor-phase wall loss in the reactors is also believed to be minimal. Lauraguais et al. (2012) found no vapor-phase wall loss of syringol and Coeur-Tourneur et al. (2010) found negligible losses for guaiacol and related methoxy and alkyl substituted benzenes. Assuming a first-order wall loss rate, $k_{\mathrm{w}} \sim 1 \times 10^{-5} \mathrm{~s}^{-1}$, a typical rate for previously tested compounds in our chamber (Loza et al., 2010), this would lead to roughly a quarter loss of syringol to the walls over the course of the experiment. Correcting for this by lowering $\Delta$ Org would lead to syringol SOA yields that are similar to those of guaiacol, but not significantly higher. We further explore the chemical basis for the differences in the yields after examining the gas-phase chemistry.

Most methoxyphenol experiments ended shortly after the hydrocarbon decay was complete. Though, even $4 \mathrm{~h}$ after 112.9 ppb syringol was completely reacted in the $3 / 29$ experiment, there was no additional SOA growth. The type of growth observed here is typified by a mechanism involving oxidation to form SOA either from first-generation products or sufficiently rapid low-volatility product formation over the course of the experiment from further generation reactions (Chan et al., 2007; Ng et al., 2006). We believe it to be the latter explanation in the case of methoxyphenol systems. The high-level of oxidation determined from the measured $\mathrm{O}: \mathrm{C}$ ratios of the SOA are indicative of multi-generation products, which is consistent with the identified gas and aerosol products discussed below.

\section{SOA formation chemistry}

We present in this section an analysis of the gas-phase mechanistic chemistry involved in SOA formation based on the CIMS traces for each system along with SOA mass growth over time. All ions unless otherwise noted were monitored during negative mode operation. CIMS signals are plotted in arbitrary units (a.u.). Discussion is focused on the guaiacol system since the off-line aerosol filter analyses complement the gas-phase data. Chemical parallels are drawn between the three systems. 


\subsection{Gas-phase oxidation}

Substituent groups such as $-\mathrm{OH}$ and $-\mathrm{OCH}_{3}$ activate more strongly the aromatic ring towards electrophilic addition of $\mathrm{OH}$ compared to the $-\mathrm{CH}_{3}$ group. Of these groups, activation potential of the ring increases in order of $-\mathrm{CH}_{3}<$ $-\mathrm{OCH}_{3}<-\mathrm{OH}$. Thus, as predicted, methoxyphenol compounds react faster with $\mathrm{OH}$ than their methyl or unsubstituted equivalents (Coeur-Tourneur et al., 2010). Methoxy and hydroxy substituent groups tend to make $\mathrm{OH}$-attack favorable at positions ortho and para to the substituents, so structures for the measured ions are proposed from chemical mechanisms assuming one of these positions of initial $\mathrm{OH}-$ attack. $\mathrm{H}$-atom abstraction from the methoxy group is expected to be small, as this path was determined to contribute $<4 \%$ in the case of methoxybenzene (Coeur-Tourneur et al., 2010).

A generation is defined as the $\mathrm{OH}$-initiated reaction of a stable (non-radical) species, and the $\mathrm{OH}$ exposure is calculated as the product of the $\mathrm{OH}$ concentration (inferred from the parent hydrocarbon decay) and the hours of irradation. Each $\mathrm{m} / \mathrm{z}$ is the sum of the signal from all isomeric structures detected by the CIMS at that ion, but are not shown explicitly in the abbreviated mechanisms and tables presented. However, from the chemical ionization method employed, we expect certain common chemical features of the proposed structures. For example, many of the transfer $[\mathrm{M}+19]^{-}$products are likely acidic (Huey et al. , 1996), containing carboxylic acid groups and/or sufficient acidic hydroxyl groups (Tables 3, 4, 6).

\subsection{Phenol chemistry}

Initial steps of the phenol gas-phase mechanism have been elucidated elsewhere (Olariu et al., 2002; Berndt and Boge, 2003). Phenol $+\mathrm{OH}$ proceeds primarily with ortho- $\mathrm{OH}$ addition to the ring, $\mathrm{O}_{2}$ addition, followed by elimination of $\mathrm{HO}_{2}$ to form 1,2-dihydroxybenzene (catechol). In the low$\mathrm{NO}_{\mathrm{x}}$ phenol experiments, CIMS ions are tracked that show successive $\mathrm{OH}$ adduct product formation up to three generations. Quinone products are also likely, though these are not detected in negative mode operation of the current CIMS technique unless they are additionally functionalized. A list of ions monitored in this system is presented in Table 3. Representative data for the phenol low- $\mathrm{NO}_{\mathrm{x}}$ system are shown in Fig. 2. Phenol, $\mathrm{C}_{6} \mathrm{H}_{6} \mathrm{O}$, is monitored at $m / z 179$, a cluster product. We do not include $m / z .113$, the fluoride transfer product, because this signal includes interference from another compound (likely a small acid) that grows in over time. Dihydroxybenzene, $\mathrm{C}_{6} \mathrm{H}_{6} \mathrm{O}_{2}$, is observed primarily as the fluoride transfer product $m / z, 129$ (DHB) with less signal observed at the $m / z, 195$ cluster product. A trace at $m / z 211$ indicates a third $\mathrm{OH}$ addition to the ring to form trihydroxybenzene (THB), $\mathrm{C}_{6} \mathrm{H}_{6} \mathrm{O}_{3}$. These time profiles are shown along with SOA growth and phenol decay for the first nine hours

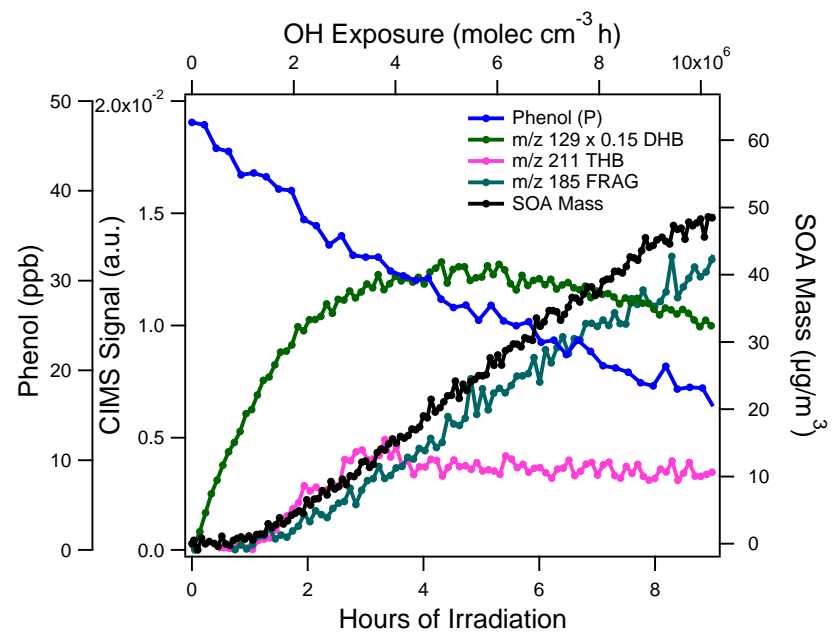

Fig. 2. Phenol low- $\mathrm{NO}_{\mathrm{x}}$ gas-phase and particle-phase development. The signal at $m / z, 129$ was scaled by a factor of 0.15 .

of irradiation (Fig. 2). SOA growth occurs coincident with the growth of $\mathrm{m} / z 211$ (THB), indicating that the transition to lower volatility products to form SOA likely occurs along the 3 rd addition of $\mathrm{OH}$ just after $\sim 1 \times 10^{6}$ molec $^{-3} \mathrm{~cm}^{-3} \mathrm{~h}$ of $\mathrm{OH}$ exposure. This is the approximate equivalent of one hour of photooxidation in the atmosphere assuming an ambient OH concentration of $\sim 1 \times 10^{6}$ molec cm$~^{-3}$. A signal at $\mathrm{m} / z$ 227 was observed to have a similar profile as $\mathrm{m} / \mathrm{z} 211$, and may be attributed to tetra hydroxybenzene (4HB, Table 3) and an epoxide isomer $\left(\mathrm{C}_{6} \mathrm{H}_{6} \mathrm{O}_{4}\right)$. A plateau in the profile is consistent with $4 \mathrm{HB}$ also contributing to the particle phase. Individual contributions from $4 \mathrm{HB}$ and the epoxide could not be determined from the signal at $m / z 227$, which was approximately one-fourth of the signal at $\mathrm{m} / \mathrm{z} 211$ (not shown for clarity). A minor amount of signal at $\mathrm{m} / z 229$ is attributed to the hydroperoxide $\mathrm{C}_{6} \mathrm{H}_{8} \mathrm{O}_{4}$.

Figure 2 also shows that the SOA is in equilibrium with $m / z .185$, which we propose to be the ring fragment $\mathrm{C}_{4} \mathrm{H}_{4} \mathrm{O}_{3}$, hydroxy butenedial, that forms from the decomposition of the bicyclic radical from phenol $+\mathrm{OH}$. Another dicarbonyl, $\mathrm{C}_{4} \mathrm{H}_{4} \mathrm{O}_{4}$, is monitored at $\mathrm{m} / z 135$, which could be the analogous ring fragment from dihydroxybenzene $+\mathrm{OH}$. These products approach the high $\mathrm{O}: \mathrm{C}$ ratios characteristic of the SOA in this system. Comparisons of the CIMS gas-phase traces and the off-line filter analyses from similar experiments performed by Nakao et al. (2011) provide additional insights. Nakao et al. (2011) utilized electrospray ionization and atmospheric pressure chemical ionization mass spectrometry (ESI/APCI-TOFMS) as well as PILS-ESI-TOFMS for analysis, though Nakao et al. (2011) noted that the PILSESI-TOFMS spectra may include water soluble gas-phase species because a denuder was not used. While Nakao et al. (2011) observed an exact mass match that corresponds with the bicyclic hydroperoxide from phenol $\left(\mathrm{C}_{6} \mathrm{H}_{8} \mathrm{O}_{6}\right)$ and another compound with a suggested formula $\mathrm{C}_{6} \mathrm{H}_{8} \mathrm{O}_{7}$ using 
Table 3. Proposed structures for CIMS ions in the phenol low- $\mathrm{NO}_{\mathrm{x}}$ system. $\mathrm{C}$ and $\mathrm{T}$ indicate the cluster and transfer product, respectively.

\begin{tabular}{|c|c|c|c|c|}
\hline Observed $\mathrm{m} / z$ & Product & Chemical Formula & Proposed Structure (one isomer shown) & Chemical Pathway \\
\hline 179 & $\mathrm{C}$ & $\mathrm{C}_{6} \mathrm{H}_{6} \mathrm{O}$ & & phenol \\
\hline 129 & $\mathrm{~T}^{\mathrm{a}}$ & $\mathrm{C}_{6} \mathrm{H}_{6} \mathrm{O}_{2}$ & & $\mathrm{DHB}=$ phenol $+\mathrm{OH}$ \\
\hline 211 & $\mathrm{C}$ & $\mathrm{C}_{6} \mathrm{H}_{6} \mathrm{O}_{3}$ & & $\mathrm{THB}=\mathrm{DHB}+\mathrm{OH}$ \\
\hline 227 & $\mathrm{C}^{\mathrm{b}}$ & $\mathrm{C}_{6} \mathrm{H}_{6} \mathrm{O}_{4}$ & & $4 \mathrm{HB}=\mathrm{THB}+\mathrm{OH}$ \\
\hline 145 & $\mathrm{~T}$ & $\mathrm{C}_{6} \mathrm{H}_{6} \mathrm{O}_{3}$ & & ring opening acid \\
\hline 161 & $\mathrm{~T}$ & $\mathrm{C}_{6} \mathrm{H}_{6} \mathrm{O}_{4}$ & & ring opening acid \\
\hline 177 & $\mathrm{~T}$ & $\mathrm{C}_{6} \mathrm{H}_{6} \mathrm{O}_{5}$ & & ring opening acid \\
\hline 185 & $\mathrm{C}^{\mathrm{c}}$ & $\mathrm{C}_{4} \mathrm{H}_{4} \mathrm{O}_{3}$ & & ring fragment \\
\hline 135 & $\mathrm{~T}^{\mathrm{d}}$ & $\mathrm{C}_{4} \mathrm{H}_{4} \mathrm{O}_{4}$ & $\mathrm{OH}$ & ring fragment \\
\hline
\end{tabular}

both techniques, we do not observe these products in the gasphase with the CIMS. It is possible that these compounds are of sufficiently low volatility at this point that they are not measurable in the gas phase. The CIMS does detect ions corresponding to several $<\mathrm{C}_{6}$ products seen in Nakao et al. (2011), including: $\mathrm{C}_{4} \mathrm{H}_{4} \mathrm{O}_{3}$ at $m / z, 185$ and $\mathrm{C}_{4} \mathrm{H}_{4} \mathrm{O}_{4}$ at $m / z$ 135 and $\mathrm{m} / \mathrm{z} 201$.

Nakao et al. (2011) also observed a series of oxygen additions, from $\mathrm{C}_{6} \mathrm{H}_{6} \mathrm{O}_{2}$ to $\mathrm{C}_{6} \mathrm{H}_{6} \mathrm{O}_{5}$, which are interpreted to possibly be a series of $\mathrm{OH}$ adduct products. Another structural possibility is that these are $\mathrm{C}_{6}$ retaining, but ring-opened carboxylic acids that would correspond to large signals in the CIMS as transfer products: $m / z, 145, \mathrm{~m} / \mathrm{z}, 161$, and $\mathrm{m} / \mathrm{z} 177$. From the time profiles of these CIMS ions, we predict that they are likely carboxylic acids even though the proposed chemical formulae are isomeric to the aromatic $\mathrm{OH}$ adducts. That is, these ion signals grow linearly with time (not shown) during the experiment duration and do not peak or plateau like their isomeric aromatic $\mathrm{OH}$ adducts. The peak/plateau of the signal from aromatic $\mathrm{OH}$ adducts is consistent with the proposed products' functionalities and potential to partition into the particle-phase, whereas these ring-opened products are of higher vapor pressure and may form throughout the experiment during continued oxidation of the phenolic products.

The presence of these products may partially explain the absence of a strong signal from a hydroperoxide $\mathrm{C}_{6} \mathrm{H}_{8} \mathrm{O}_{4}$ at $\mathrm{m} / \mathrm{z} 229$. The alkylperoxy radical preferentially isomerizes to form the bicyclic peroxy radical and decomposes from a bicyclic alkoxy radical to $<\mathrm{C}_{6}$ fragments (often dicarbonyl) as mentioned above. However, Birdsall et al. (2010) observed evidence that the alkylperoxy radical may also participate in chemistry that regenerates $\mathrm{OH}$ and opens the ring (alternate route to alkoxy radical formation without first forming the bicyclic peroxy radical). This was found to be a more minor pathway also via $\mathrm{RO}_{2}+\mathrm{HO}_{2} \rightarrow \mathrm{RO}+\mathrm{OH}+\mathrm{O}_{2}$ for the case of toluene photooxidation. This results in an aromatic alkoxy radical and ring-opening to form methylhexadienedial, $\mathrm{a}_{7}$ dialdehyde (preserving the carbon backbone). Though this route was more prominent under low $\left[\mathrm{O}_{2}\right]$ conditions, Birdsall et al. (2010) also observed this product at pressures more similar to the atmosphere where bicyclic peroxy radical formation is expected to dominate and form dicarbonyl ring fragments. Thus, this ring-opening dicarbonyl pathway may also be present in this study, while minor compared to production of dicarbonyl fragments. 
Table 4. Proposed structures for CIMS ions in the guaiacol low- $\mathrm{NO}_{\mathrm{x}}$ system. $\mathrm{C}$ and $\mathrm{T}$ indicate the cluster and transfer product, respectively.

\begin{tabular}{|c|c|c|c|c|}
\hline Observed $m / z$ & Product & Chemical Formula & Proposed Structure (one isomer shown) & Chemical Pathway $^{\mathrm{a}}$ \\
\hline 209 & $C^{b}$ & $\mathrm{C}_{7} \mathrm{H}_{8} \mathrm{O}_{2}$ & & guaiacol \\
\hline 259 & $\mathrm{C}$ & $\mathrm{C}_{7} \mathrm{H}_{10} \mathrm{O}_{5}$ & & (1) hydroperoxide \\
\hline 225 & $\mathrm{C}$ & $\mathrm{C}_{7} \mathrm{H}_{8} \mathrm{O}_{3}$ & & (2) $\mathrm{G}+\mathrm{OH}=$ guaiacol $+\mathrm{OH}$ \\
\hline 241 & $\mathrm{C}$ & $\mathrm{C}_{7} \mathrm{H}_{8} \mathrm{O}_{4}$ & & (2) $\mathrm{G}+2 \mathrm{OH}=$ guaiacol $+2 \mathrm{OH}$ \\
\hline 191 & $\mathrm{~T}^{\mathrm{c}}$ & $\mathrm{C}_{7} \mathrm{H}_{8} \mathrm{O}_{5}$ & & (2) $\mathrm{G}+3 \mathrm{OH}=$ guaiacol $+3 \mathrm{OH}$ \\
\hline 175 & $\mathrm{~T}$ & $\mathrm{C}_{7} \mathrm{H}_{8} \mathrm{O}_{4}$ & OH & ring opening product \\
\hline 257 & $\mathrm{C}^{\mathrm{d}}$ & $\mathrm{C}_{7} \mathrm{H}_{8} \mathrm{O}_{5}$ & SH & (3aii) EPOX and (2) $\mathrm{G}+3 \mathrm{OH}$ \\
\hline 149 & $\mathrm{~T}$ & $\mathrm{C}_{5} \mathrm{H}_{6} \mathrm{O}_{4}$ & & (3aiii) ring fragment \\
\hline 187 & $\mathrm{C}$ & $\mathrm{C}_{4} \mathrm{H}_{6} \mathrm{O}_{3}$ & & (3aiii) ring fragment \\
\hline 199 & $\mathrm{C}$ & $\mathrm{C}_{5} \mathrm{H}_{6} \mathrm{O}_{3}$ & 0 & (3aiii) ring fragment \\
\hline 107 & $\mathrm{~T}$ & $\mathrm{C}_{3} \mathrm{H}_{4} \mathrm{O}_{3}$ & & (3aiii) ring fragment \\
\hline 189 & $\mathrm{C}$ & $\mathrm{C}_{3} \mathrm{H}_{4} \mathrm{O}_{4}$ & & (3aiii) ring fragment \\
\hline 243 & $\mathrm{~T}$ & $\mathrm{C}_{6} \mathrm{H}_{6} \mathrm{O}_{5}$ & & (3b) $\mathrm{C}_{6}$ bicyclic ketone \\
\hline 129 & $\mathrm{~T}^{\mathrm{e}}$ & $\mathrm{C}_{6} \mathrm{H}_{6} \mathrm{O}_{2}$ & & (4) Methoxy Loss \\
\hline
\end{tabular}

${ }^{a}$ Numbers indicate correspondence with pathways outlined in mechanism (Fig. 4); ${ }^{\mathrm{b}} \mathrm{m} / \mathrm{z} 143$ is also present as $\mathrm{C}_{7} \mathrm{H}_{8} \mathrm{O}_{2}$, but is lower signal than at $m / z 209$; ${ }^{\mathrm{A}}$ Also includes signal from $\mathrm{C}_{7} \mathrm{H}_{8} \mathrm{O}_{5}$ ring opening acid; ${ }^{\mathrm{d}}$ Includes contributions from $\mathrm{G}+3 \mathrm{OH}$ along pathway 2 in Fig. 4 ; ${ }^{\mathrm{e}} \mathrm{m} / z$, 195 is also present as $\mathrm{C}_{6} \mathrm{H}_{6} \mathrm{O}_{2}$, but is lower signal than at $\mathrm{m} / \mathrm{z} 129$

Figure 3 outlines a potential mechanism employing this scheme to form these multifunctional $\mathrm{C}_{6}$ carboxylic acids from phenol, dihydroxybenzene, and trihydroxybenzene. The difference between the products proposed here and those of Birdsall et al. (2010) is that the hydroxy group placement results in carboxylic acid functionality. We note that depending on the hydroxy group placement on the ring, isomeric hydroxy dicarbonyl products are also likely and can contribute to these ion signals as well. OH regeneration could also come from photolysis of a hydroperoxide producing a favorable 
Table 5. SOA products observed in UPLC/(-)ESI-TOFMS offline filter analysis for the guaiacol low- $\mathrm{NO}_{\mathrm{x}}$ system.

\begin{tabular}{cccc}
\hline$[\mathrm{M}-\mathrm{H}]^{-}$ & Meas. Mass & $\begin{array}{c}\text { Suggested Chemical } \\
\text { Formula }(\mathrm{M})\end{array}$ & $\begin{array}{c}\text { Error* } \\
(\mathrm{mDa})\end{array}$ \\
\hline 189 & 189.0378 & $\mathrm{C}_{7} \mathrm{H}_{10} \mathrm{O}_{6}$ & -2.1 \\
219 & 219.014 & $\mathrm{C}_{7} \mathrm{H}_{8} \mathrm{O}_{8}$ & -0.1 \\
147 & 147.0266 & $\mathrm{C}_{5} \mathrm{H}_{8} \mathrm{O}_{5}$ & -2.6 \\
157 & 157.0113 & $\mathrm{C}_{6} \mathrm{H}_{6} \mathrm{O}_{5}$ & -2.4 \\
133 & 133.0133 & $\mathrm{C}_{4} \mathrm{H}_{6} \mathrm{O}_{5}$ & -2.4 \\
149 & 149.0072 & $\mathrm{C}_{4} \mathrm{H}_{6} \mathrm{O}_{6}$ & -1.4 \\
205 & 205.0327 & $\mathrm{C}_{7} \mathrm{H}_{10} \mathrm{O}_{7}$ & 2.1 \\
145 & 145.048 & $\mathrm{C}_{6} \mathrm{H}_{10} \mathrm{O}_{4}$ & -2.1 \\
163 & 163.0233 & $\mathrm{C}_{5} \mathrm{H}_{8} \mathrm{O}_{6}$ & -1 \\
203 & 203.0177 & $\mathrm{C}_{7} \mathrm{H}_{8} \mathrm{O}_{7}$ & -1.5 \\
171 & 171.0279 & $\mathrm{C}_{7} \mathrm{H}_{8} \mathrm{O}_{5}$ & -1.4 \\
169 & 169.0124 & $\mathrm{C}_{7} \mathrm{H}_{6} \mathrm{O}_{5}$ & -1.3 \\
173 & 173.0428 & $\mathrm{C}_{7} \mathrm{H}_{10} \mathrm{O}_{5}$ & -2.2 \\
115 & 115.0004 & $\mathrm{C}_{4} \mathrm{H}_{4} \mathrm{O}_{4}$ & -2.7 \\
129 & 129.0175 & $\mathrm{C}_{5} \mathrm{H}_{6} \mathrm{O}_{4}$ & -1.3 \\
\hline
\end{tabular}

* The error in the accurate mass measurements is the difference between the theoretical mass of the suggested molecular formulae and the measured mass of the ion.

alkoxy radical for ring opening, though we would not expect this to be significant on such a quick timescale that is consistent with negligible signal from the hydroperoxide. All CIMS traces for proposed ring opening acids and ring fragments share a similar trend of constant linear growth over time (not shown). Many of these trend with the aerosol mass (e.g. $\mathrm{m} / \mathrm{z}$ 185 mentioned earlier), indicating that aerosol growth continues to proceed with the generation of ring opening and fragmentation processes.

\subsection{Guaiacol chemistry}

Figure 4 presents proposed oxidation pathways for the guaiacol system under low- $\mathrm{NO}_{\mathrm{x}}$ conditions. Solid boxed structures indicate that the expected $\mathrm{m} / \mathrm{z}$ from the chemical ionization reactions in the CIMS for that compound was detected. The $\mathrm{m} / \mathrm{z}$ monitored is indicated, as are proposed $\mathrm{C}_{\mathrm{x}} \mathrm{H}_{\mathrm{y}} \mathrm{O}_{\mathrm{z}}$ formulas and molecular weights. A list of ions monitored in this system is presented in Table 4. Chemical formulas shown in red indicate correspondence with a suggested $\mathrm{C}_{\mathrm{x}} \mathrm{H}_{\mathrm{y}} \mathrm{O}_{\mathrm{z}}$ for accurate mass observations in filter data (Table 5). The particular structures in Fig. 4 indicate potential structures for the accurate mass suggested chemical formulae and the mechanism does not explicitly present all potential isomeric structures. The boxed colors correspond with the colors used for ion time traces as measured by the CIMS and included in Fig. 5.

Guaiacol gas-phase oxidation proceeds with $\mathrm{OH}$ addition to the ring, followed by reaction with oxygen to form an organic peroxy radical. Under the experimental conditions, the fate of this $\mathrm{RO}_{2}$ radical is reaction with $\mathrm{HO}_{2}$ to form a hy- droperoxide (Fig. 4, Pathway 1), elimination of $\mathrm{HO}_{2}$ to retain aromaticity (Fig. 4, Pathway 2), or isomerization to the bicyclic radical (Fig. 4, Pathway 3).

\subsubsection{Pathway 1: $\mathrm{RO}_{2}+\mathrm{HO}_{2}$}

Despite predominant conditions of $\mathrm{RO}_{2}+\mathrm{HO}_{2}$ chemistry, we do not observe strong signals in the CIMS measurements for potential hydroperoxides, as is similar to the case of phenol. A small trace at $\mathrm{m} / z 259$ suggests that there is slight production of the hydroperoxide $\mathrm{C}_{7} \mathrm{H}_{10} \mathrm{O}_{5}$. The off-line filter analysis does reveal a small contribution from a corresponding accurate mass measurement (Table 5). More significant signals in the CIMS are presented in Fig. 5, demonstrating that the preferred routes are to preserve aromaticity or involve isomerization to the bicyclic radical. This observation is consistent with previous studies on aromatic systems (Calvert et al., 2002; Bloss et al., 2005; Johnson et al., 2005; Birdsall et al., 2010).

\subsubsection{Pathway 2: continuous $\mathrm{OH}$ addition to ring}

The general chemical development of the consecutive $\mathrm{OH}$ addition pathways in the guaiacol low- $\mathrm{NO}_{\mathrm{x}}$ system are tracked in Fig. 5. Figure 4, Pathway 2 is marked by $\mathrm{m} / \mathrm{z}$ 225 on the CIMS, a cluster product for the guaiacol $\mathrm{OH}_{-}$ adduct product, $\mathrm{C}_{7} \mathrm{H}_{8} \mathrm{O}_{3}$ and denoted as $\mathrm{G}+\mathrm{OH}$. Successive $\mathrm{OH}$ addition products are monitored at $16 \mathrm{amu}$ increments at $\mathrm{m} / z 241$ and $\mathrm{m} / \mathrm{z} 257$, for $\mathrm{C}_{7} \mathrm{H}_{8} \mathrm{O}_{4}$ denoted as $\mathrm{G}+2 \mathrm{OH}$ and $\mathrm{C}_{7} \mathrm{H}_{8} \mathrm{O}_{5}$ denoted as $\mathrm{G}+3 \mathrm{OH}$, respectively. The third $\mathrm{OH}$ adduct can be tracked at both the transfer and the cluster products, $m / z 191$ and $m / z$ 257, respectively. However, $\mathrm{m} / \mathrm{z}, 257$ includes the combined signal of rapid epoxide formation and the later formed third generation $\mathrm{OH}$ adduct. A signal at $\mathrm{m} / \mathrm{z}, 191$ is predominantly the third generation $\mathrm{OH}$ adduct during the first $8 \mathrm{~h}$ until another product (likely an acid) grows in at this $\mathrm{m} / \mathrm{z}$. The first $\mathrm{OH}$-adduct product $(\mathrm{m} / \mathrm{z}$ 225) is short-lived due to further activation of the ring by the additional hydroxy group. Formation of $\mathrm{C}_{7} \mathrm{H}_{8} \mathrm{O}_{4}$ monitored at $\mathrm{m} / \mathrm{z} 241$ follows promptly. The signal at $\mathrm{m} / \mathrm{z}, 191$ (not shown) was observed to follow after $m / z 241$, indicating that third $\mathrm{OH}$ addition is achieved. $\mathrm{C}_{7} \mathrm{H}_{8} \mathrm{O}_{5}$ is also a proposed chemical formula for a product observed in the filter analysis (Table 5), suggesting that the third $\mathrm{OH}$ adduct is of sufficiently low volatility to partition to the particle phase.

\subsubsection{Pathway 3: isomerization to bicyclic radical}

The bicyclic peroxy radical can react with $\mathrm{HO}_{2}$ to form the bicyclic hydroperoxide $\mathrm{C}_{7} \mathrm{H}_{10} \mathrm{O}_{7}$ (Fig. 4, Pathway 3ai), however, no evidence exists for this product in the CIMS. This is analogous with the bicyclic hydroperoxide from the phenolic case. However, if this product is formed, it already has a low vapor pressure and an $\mathrm{O}: \mathrm{C}$ of 1 , and would likely partition into the aerosol phase. Filter data also indicate the presence of $\mathrm{C}_{7} \mathrm{H}_{10} \mathrm{O}_{7}$ in the particle-phase (Table 5). The majority of 


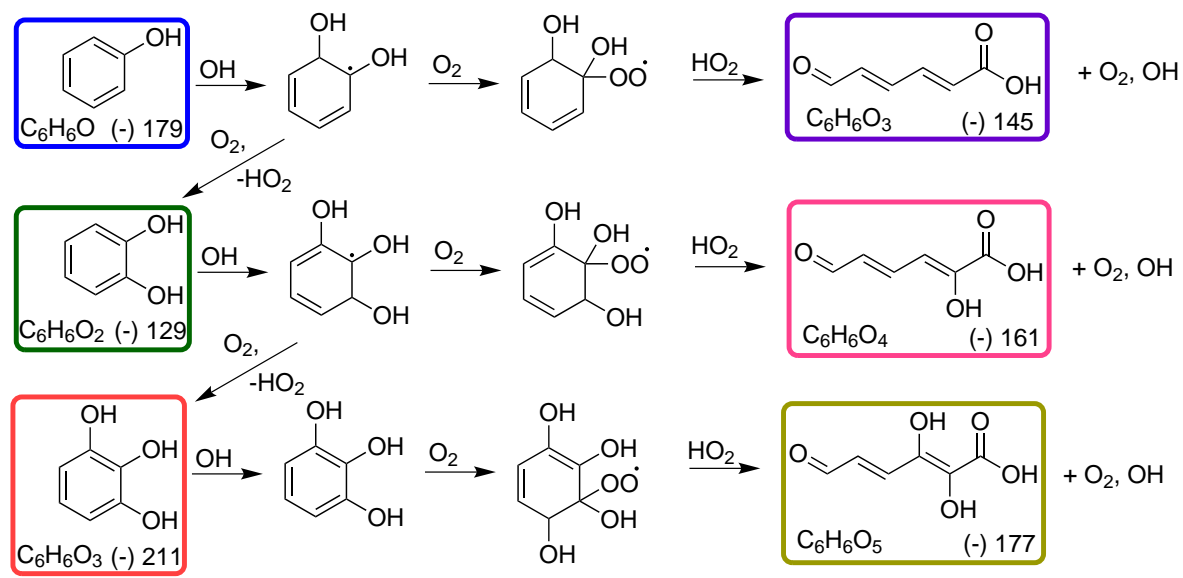

Fig. 3. Proposed pathway for gas-phase production of $\mathrm{C}_{6}$ carboxylic acids in the phenol low- $\mathrm{NO}_{\mathrm{x}}$ system. Boxed structures indicate that the expected $\mathrm{m} / \mathrm{z}$ from the chemical ionization reactions in the CIMS for that compound was detected.

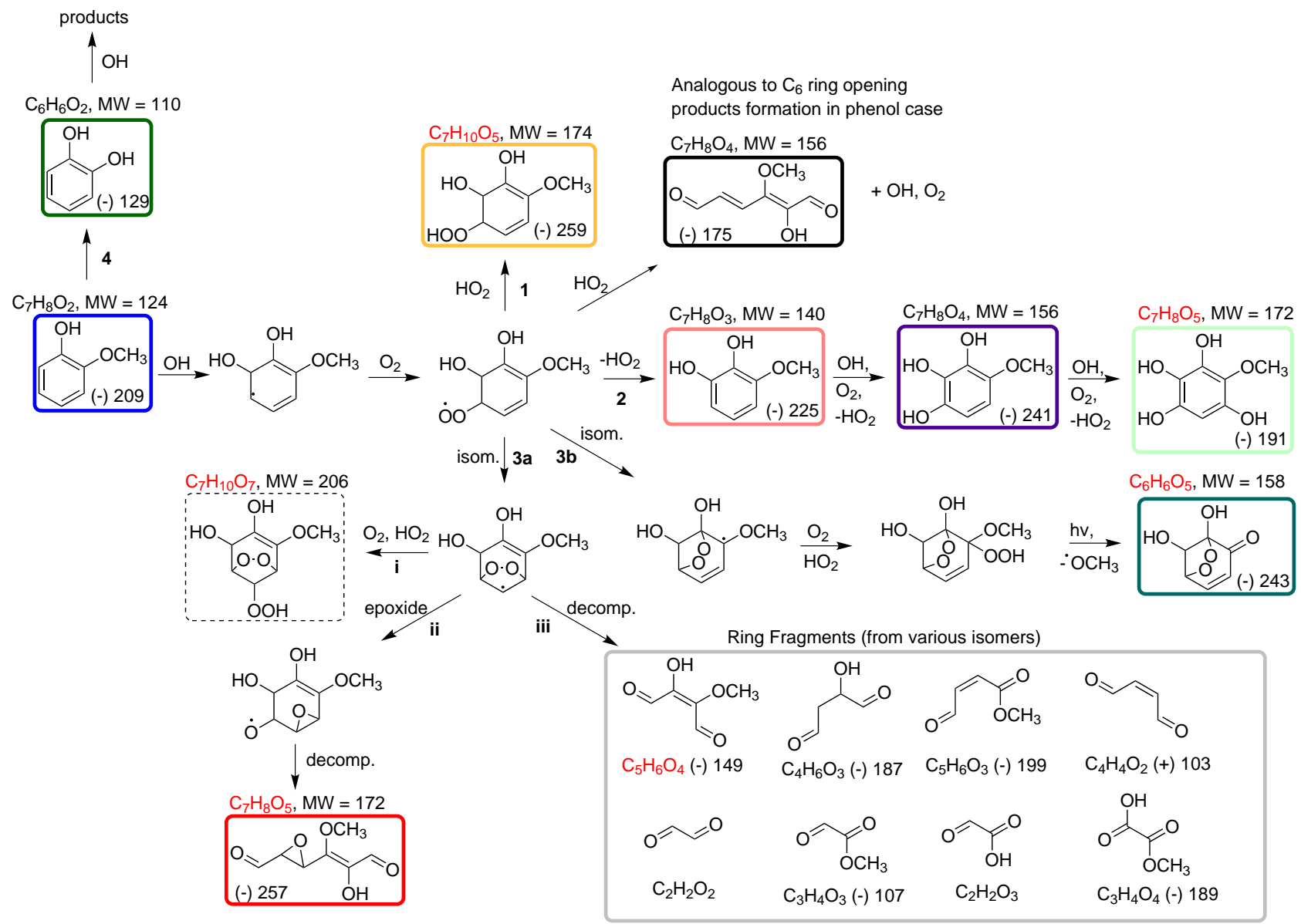

Fig. 4. Proposed mechanism for guaiacol low- $\mathrm{NO}_{\mathrm{x}}$ oxidation. Boxed structures indicate that the expected $\mathrm{m} / \mathrm{z}$ from the chemical ionization reactions in the CIMS for that compound was detected. Chemical formulae in red correspond with those proposed for the filter accurate mass aerosol measurements. 


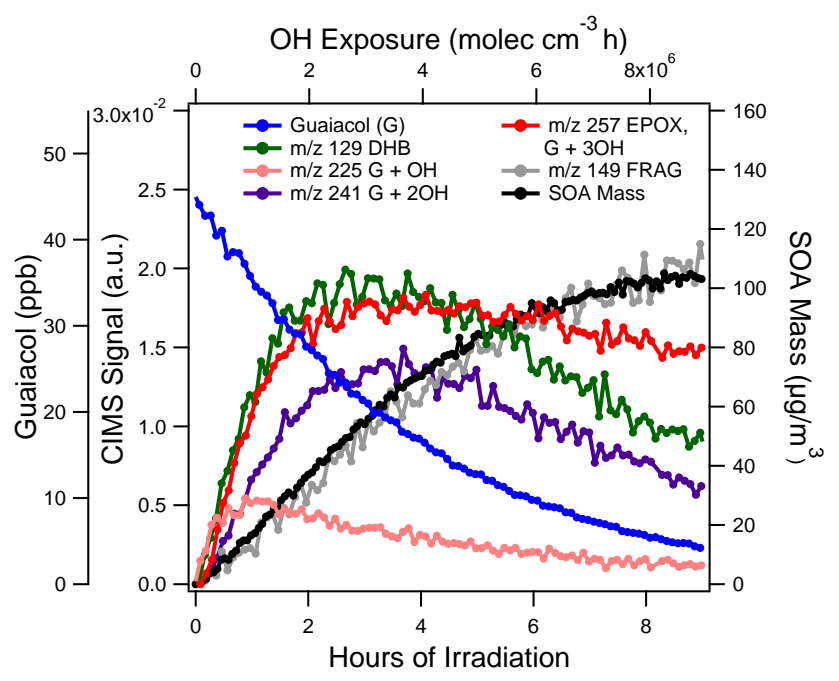

Fig. 5. Selected traces in guaiacol low- $\mathrm{NO}_{\mathrm{x}}$ gas-phase and particlephase development.

the filter data guaiacol products exhibit $\mathrm{O}: \mathrm{C}$ ratio $>0.7$, and the average bulk $\mathrm{O}: \mathrm{C}$ ratio as measured by the AMS is 0.89 , so it is likely these hydroperoxide species may immediately partition and become further processed in the particle phase. Ofner et al. (2011) found $\mathrm{O}: \mathrm{C}$ ratios of $0.3-1$, which were attributed to products that are likely highly oxygenated benzenes and conjugated olefins.

Alternatively, the bicyclic radical can rearrange, breaking the oxygen bridge to form an epoxide and open the ring (Fig. 4, Pathway 3aii). There is evidence of a significant epoxide (EPOX) route that grows in early with the dihydroxybenzene route (Fig. 5). The epoxide is monitored at $m / z$ 257, the cluster product of $\mathrm{C}_{7} \mathrm{H}_{8} \mathrm{O}_{5}$ (Fig. 5), though there is some later contribution from the third generation $\mathrm{OH}$ adduct, as mentioned earlier. The epoxide will continue to react with $\mathrm{OH}$ to generate more functionalized molecules that will likely contribute to SOA formation.

The bicyclic radical can also decompose to several fragments as shown in the box in Fig. 4, Pathway 3aiii. A major fragment is observed at $\mathrm{m} / \mathrm{z} 149$, which could be the methoxy analog to the phenolic fragment, hydroxybutenedial $\left(\mathrm{C}_{4} \mathrm{H}_{4} \mathrm{O}_{3}\right)$ at $\mathrm{m} / z$ 185. We propose that $\mathrm{m} / z, 149$ is a methoxy-hydroxy-butenedial fragment, $\mathrm{C}_{5} \mathrm{H}_{6} \mathrm{O}_{4} \cdot \mathrm{C}_{5} \mathrm{H}_{6} \mathrm{O}_{4}$ is also an accurate mass assignment for a product observed in the filter data (Table 5). The $\mathrm{m} / \mathrm{z} 149$ trace has a similar profile to the SOA mass curve, indicating that it is in equilibrium with the particle phase (Fig. 5). Other possible fragments are observed at ions indicated in the mechanism. The $<\mathrm{C}_{4}$ fragments approach $\mathrm{O}: \mathrm{C}$ values $>1$, and the $\mathrm{C}_{4}$ and $\mathrm{C}_{5}$ fragments would likely undergo further oxidation in the gas phase and then possibly contribute to the particle phase. The fate of butenedial $\left(\mathrm{C}_{4} \mathrm{H}_{4} \mathrm{O}_{2}\right)$ has been described elsewhere (Calvert et al., 2002; Bloss et al., 2005).
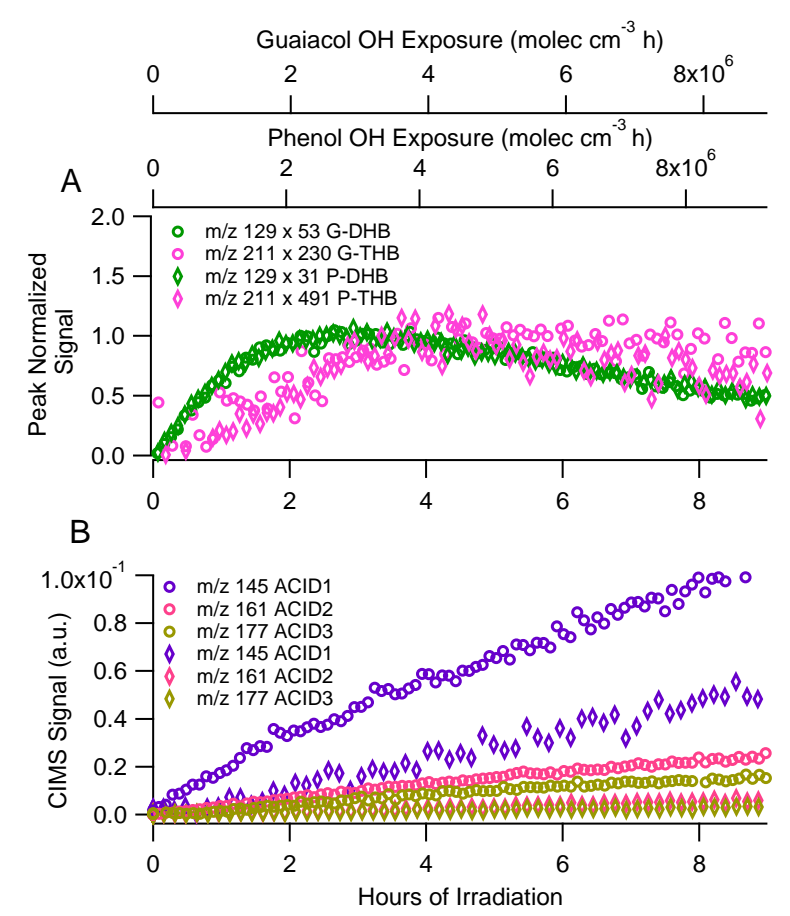

Fig. 6. Common chemical routes in the phenol and guaiacol low$\mathrm{NO}_{\mathrm{x}}$ systems. (A) Dihydroxybenzene routes in phenol (diamonds) and guaiacol (open circles). Each CIMS trace is normalized by the peak value. (B) Common acids in phenol (diamonds) and guaiacol (open circles).

\subsubsection{Pathway 4: methoxy loss route}

The early growth of a strong signal at $\mathrm{m} / \mathrm{z} 129$ (Fig. 5) and a matching time profile at $m / z, 195$ upon irradiation suggests that dihydroxybenzene $\left(\mathrm{C}_{6} \mathrm{H}_{6} \mathrm{O}_{2}\right)$ is somehow formed from guaiacol $\left(\mathrm{C}_{7} \mathrm{H}_{8} \mathrm{O}_{3}\right)+\mathrm{OH}$ in the gas phase. This is further supported by matching time profiles from the guaiacol and phenol systems for dihydroxybenzene (DHB) and its oxidation to trihydroxybenzene (THB) in Fig. 6a, as well as growth of the proposed $\mathrm{C}_{6}$ ring opening acids (Fig. 6b). In the guaiacol system, the raw signal at $m / z 211$ includes contributions from the ${ }^{18} \mathrm{O}$ natural isotope peak of the guaiacol cluster product and trihydroxybenzene. The signal at $\mathrm{m} / \mathrm{z} 211$ has been corrected to reflect only the contribution from trihydroxybenzene (G-THB). There is negligible signal at $m / z, 227$ in the guaiacol system, indicating that the dihydroxybenzene that is formed proceeds only to one more step of oxidation before the carbon along this route is incorporated into pathways besides continuous $\mathrm{OH}$ adduct formation. Rather, the carbon likely ends up in production of ring-opened acids as shown in Fig. 6b.

A trace at $m / z 243$ is present in the guaiacol system, though because there is negligible signal at $\mathrm{m} / \mathrm{z}, 227$, it is unlikely that this ion is part of the $\mathrm{OH}$ adduct series from dihydroxybenzene as $\mathrm{C}_{6} \mathrm{H}_{6} \mathrm{O}_{5}$. Still, an exact mass match for $\mathrm{C}_{6} \mathrm{H}_{6} \mathrm{O}_{5}$ is the fourth highest product (in terms of area counts) of 
constituents identified in the filter data, and $\mathrm{m} / \mathrm{z} 243$ follows the SOA trace indicating that it may be an important contributor to the particle phase. In the event that the radical placement occurs on the carbon containing the methoxy group during formation of the bicyclic radical, carbon loss may occur by removal of a methoxy group. The ether alky radical will react with $\mathrm{O}_{2}$ to generate an ether alkyl peroxy radical. Collins et al. (2005) proposed that photooxidation of diisopropyl ether in the absence of $\mathrm{NO}_{\mathrm{x}}$ (with $\mathrm{RO}_{2}+\mathrm{HO}_{2}$ reactions dominating) likely resulted in the formation of hydroperoxide species that could then undergo decomposition, photolysis, or reaction with $\mathrm{OH}$. Photolysis of the hydroperoxy group in the current methoxyphenol case would result in an alkoxy radical and elimination of the methoxy group to form a ketone. This leads to formation of a $\mathrm{C}_{6}$ bicyclic ketone product as outlined in Pathway $3 \mathrm{~b}$ of Fig. 4. The mechanism and structure for this particle-phase product remain tentative, as the proposed structure may be unstable and participate in additional condensation reactions.

\subsubsection{Guaiacol aerosol-phase products}

The off-line filter analysis suggests that there are additional chemical pathways for this system than those inferred from the gas-phase CIMS measurements. The top fifteen ions (by highest peak area) are presented in Table 5 along with measured masses and suggested corresponding chemical formulae. Of the suggested chemical formulae, the $\mathrm{O}: \mathrm{C}$ ranges from 0.67 to 1.5 . The $<\mathrm{C}_{7}$ components are likely ring fragments that have undergone further oxidation to achieve such high O:C compared to those shown in Fig. 4, Pathway 3aiii. Of the $\mathrm{C}_{7}$ retaining products listed in Table 5, all suggested chemical formulae except $\mathrm{C}_{7} \mathrm{H}_{5} \mathrm{O}_{5}$ can be explained by first-generation products along pathways 1, 2, 3ai, and 3aii (Fig. 4) and the analogous pathways in higher generation chemistry from the $\mathrm{OH}$ adducts. Similar structures to those proposed here have been observed previously in EI-MS analyses (Justesen, 2001). However, since many corresponding signals are not observed in the CIMS, it is also possible that a number of these highly oxygenated $\left(>\mathrm{O}_{5}\right)$ species may be formed in the particle phase, as evidenced in Ofner et al. (2011) for aerosol from guaiacol and catechol.

Previous study by Ofner et al. (2011) reports that the most important functional groups of generated SOA from guaiacol and catechol include carboxylic acids, carboxylic anhydrides and lactones or esters. While carboxylic acids can form as ring fragmentation products depending on the particular conformation of the bicyclic radical, the observation of carboxylic anhydrides and lactones suggests potential for additional intra- and inter-molecular reactions that may occur in the particle-phase involving the carbonyl and methoxy groups of SOA products. Ofner et al. (2011) also observe the degradation of the methoxy group during SOA formation from guaiacol, and finds this degradation to be more pronounced under wet conditions. This supports additional chemistry (likely in the particle phase) that goes beyond the proposed gas-phase products in Fig. 4.

\subsection{Syringol chemistry}

The chemistry of syringol under low- $\mathrm{NO}_{\mathrm{x}}$ conditions leads to rapid formation of a rich diversity of gas-phase products and SOA growth. Whereas at least two generations of $\mathrm{OH}$ oxidation of phenol are required to generate SOA, guaiacol and syringol produce SOA in the first generation. This is clear when comparing the SOA mass curves between systems in Figs. 2, 5 , and 7. As expected, syringol is more reactive than guaiacol because of its additional methoxy group. Syringol is detected primarily at the transfer $[\mathrm{M}+19]^{-}, m / z, 173$, with some signal at the cluster product $[\mathrm{M}+85]^{-}, \mathrm{m} / \mathrm{z} 239$. This is the opposite of guaiacol, the signal of which is found predominantly at the cluster product. This suggests that the extra methoxy group on syringol compared to guaiacol leads to an enhancement towards greater acidity to be seen predominantly at the transfer product $(\mathrm{m} / \mathrm{z}$ 173). This shift is observed for many of the ions in the syringol case that are analogous to the guaiacol system. CIMS ions monitored in this system are presented in Table 6.

Syringol oxidation chemistry seems to undergo similar routes as guaiacol with analogous ions monitored by the CIMS for the following pathways: (1) hydroperoxide formation, (2) $\mathrm{OH}$ adduct formation up to two to three generations, and (3) epoxide and $<\mathrm{C}_{8}$ ring fragment formation from decomposition of the bicyclic radical. These pathways are highlighted in Fig. 7a by selected ions at 189 and 271 for $\mathrm{OH}$ adducts $\mathrm{C}_{8} \mathrm{H}_{10} \mathrm{O}_{4}(\mathrm{~S}+\mathrm{OH})$ and $\mathrm{C}_{8} \mathrm{H}_{10} \mathrm{O}_{5}(\mathrm{~S}+2 \mathrm{OH})$, respectively, $m / z, 287$ for the $\mathrm{C}_{8} \mathrm{H}_{10} \mathrm{O}_{6}$ syringol epoxide (SEPOX), and a $\mathrm{C}_{6} \mathrm{H}_{8} \mathrm{O}_{5}$ ring fragment (FRAG) at $\mathrm{m} / z$ 245. A minor contribution from the $\mathrm{C}_{8} \mathrm{H}_{12} \mathrm{O}_{6}$ syringol hydroperoxide at $\mathrm{m} / \mathrm{z} 289$ was observed in the CIMS spectra and is not shown.

These routes seem to be minor, however, in comparison to those that favor immediate scission of the $\mathrm{C}_{8}$ backbone (Fig. 7). Many of the higher signals in the CIMS are at $\mathrm{m} / \mathrm{z}$ values that can only be reasonably explained by $<\mathrm{C}_{8}$ molecular formulas. For example, major traces are from ions at $\mathrm{m} / \mathrm{z}$ 275 (Fig. 7b), likely $\mathrm{C}_{7} \mathrm{H}_{10} \mathrm{O}_{6}$. A signal was also observed in the CIMS spectra at $m / z 291$, possibly $\mathrm{C}_{7} \mathrm{H}_{10} \mathrm{O}_{7}$, and is not shown. There is also evidence of methoxy and hydroxy exchanges and eliminations, providing even more diversity of masses in the CIMS spectra from syringol photooxidation. More detailed analyses on chemical structure would be required to confirm precise mechanisms.

For syringol, the immediate loss of carbon through novel chemical pathways (methoxy group elimination or exchange with hydroxy) is more evident in multiple routes than was observed in the case of guaiacol. Figure 8 proposes several possibilities of syringol conversion to compounds with fewer methoxy groups. Each of these pathways has representative 
Table 6. Proposed structures for CIMS ions in the syringol low- $\mathrm{NO}_{\mathrm{x}}$ system. $\mathrm{C}$ and $\mathrm{T}$ indicate the cluster and transfer product, respectively.

\begin{tabular}{|c|c|c|c|c|}
\hline Observed $m / z$ & Product & Chemical Formula & Proposed Structure (one isomer shown) & Chemical Pathway $^{a}$ \\
\hline 173 & $\mathrm{~T}^{\mathrm{b}}$ & $\mathrm{C}_{8} \mathrm{H}_{10} \mathrm{O}_{3}$ & & syringol \\
\hline 189 & $\mathrm{~T}$ & $\mathrm{C}_{8} \mathrm{H}_{10} \mathrm{O}_{4}$ & & $\mathrm{~S}+\mathrm{OH}=$ syringol $+\mathrm{OH}$ \\
\hline 271 & $\mathrm{C}$ & $\mathrm{C}_{8} \mathrm{H}_{10} \mathrm{O}_{5}$ & & $\mathrm{~S}+2 \mathrm{OH}=$ syringol $+2 \mathrm{OH}$ \\
\hline 289 & $\mathrm{C}$ & $\mathrm{C}_{8} \mathrm{H}_{12} \mathrm{O}_{6}$ & & hydroperoxide \\
\hline 225 & $\mathrm{C}$ & $\mathrm{C}_{7} \mathrm{H}_{8} \mathrm{O}_{3}$ & & (a) $\mathrm{G}+\mathrm{OH}=$ guaiacol $+\mathrm{OH}$ \\
\hline 211 & $\mathrm{C}$ & $\mathrm{C}_{6} \mathrm{H}_{6} \mathrm{O}_{3}$ & & (b) $\mathrm{THB}=\mathrm{DHB}+\mathrm{OH}$ \\
\hline 209 & $\mathrm{C}$ & $\mathrm{C}_{7} \mathrm{H}_{8} \mathrm{O}_{2}$ & & (c) guaiacol \\
\hline 129 & $\mathrm{~T}^{\mathrm{c}}$ & $\mathrm{C}_{6} \mathrm{H}_{6} \mathrm{O}_{2}$ & & (d) $\mathrm{DHB}=$ phenol $+\mathrm{OH}$ \\
\hline 205 & $\mathrm{~T}^{\mathrm{d}}$ & $\mathrm{C}_{8} \mathrm{H}_{10} \mathrm{O}_{5}$ & & ring opening product \\
\hline 287 & $\mathrm{C}$ & $\mathrm{C}_{8} \mathrm{H}_{10} \mathrm{O}_{6}$ & & SEPOX \\
\hline 245 & $\mathrm{C}$ & $\mathrm{C}_{6} \mathrm{H}_{8} \mathrm{O}_{5}$ & & ring fragment \\
\hline 149 & $\mathrm{~T}$ & $\mathrm{C}_{5} \mathrm{H}_{6} \mathrm{O}_{4}$ & & ring fragment \\
\hline 185 & $\mathrm{C}$ & $\mathrm{C}_{4} \mathrm{H}_{4} \mathrm{O}_{3}$ & & ring fragment \\
\hline 203 & $\mathrm{C}$ & $\mathrm{C}_{4} \mathrm{H}_{6} \mathrm{O}_{4}$ & $0^{\prime}$ & ring fragment \\
\hline 275 & $\mathrm{C}$ & $\mathrm{C}_{7} \mathrm{H}_{10} \mathrm{O}_{6}$ & none proposed & $\mathrm{C}_{8}$ scission \\
\hline 291 & $\mathrm{C}$ & $\mathrm{C}_{7} \mathrm{H}_{10} \mathrm{O}_{7}$ & none proposed & $\mathrm{C}_{8}$ scission \\
\hline
\end{tabular}

${ }^{a}$ Letters indicate correspondence with pathways outlined in mechanism (Fig. 8).

${ }^{b} \mathrm{~m} / 2239$ is also present as $\mathrm{C}_{8} \mathrm{H}_{10} \mathrm{O}_{3}$, but is lower signal than at $\mathrm{m} / \mathrm{z} 173$.

${ }^{c} \mathrm{~m} / z 195$ is also present as $\mathrm{C}_{6} \mathrm{H}_{6} \mathrm{O}_{2}$, but is lower signal than at $\mathrm{m} / \mathrm{z} 129$.

d Includes contributions from $\mathrm{S}+2 \mathrm{OH}$ as well as ring opening product.

ions that also appear in the guaiacol case, though they are not necessarily the same mechanistically.

Analogous to the formation of dihydroxybenzene in the case of guaiacol $+\mathrm{OH}$, the early growth of $\mathrm{m} / \mathrm{z} 225$ (presumably $\left.\mathrm{C}_{7} \mathrm{H}_{8} \mathrm{O}_{3}\right)$ suggests that hydroxy guaiacol $(\mathrm{G}+\mathrm{OH})$ may form from syringol $+\mathrm{OH}$ (Figs. 7b, 8, Pathway a). Another possibility is the complete exchange of both methoxy groups for hydroxy groups, resulting in trihydroxybenzene (THB) monitored at $m / z, 211$ (Figs. 7b, 8, Pathway b). Formation of guaiacol is also evident by matching time profiles growing in at $\mathrm{m} / \mathrm{z} 143$ and 209 (Figs. 7b, 8, Pathway c). Growth of dihydroxybenzene (DHB) at $\mathrm{m} / z, 129$ and $\mathrm{m} / z 195$ is observed later in the experiment, likely from conversion of guaiacol (Fig. 8, Pathway d). Observation of signal at $\mathrm{m} / \mathrm{z}, 257$ (the guaiacol epoxide and third $\mathrm{OH}$ adduct) supports that there is a guaiacol channel in syringol photooxidation, and is not 


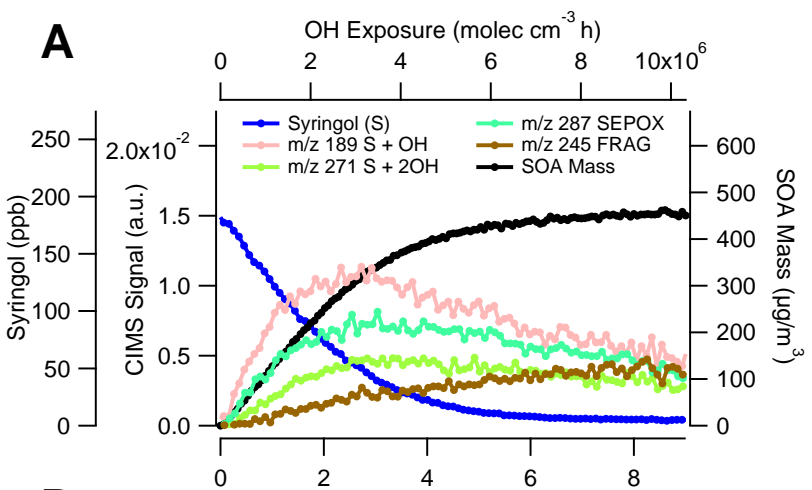

B

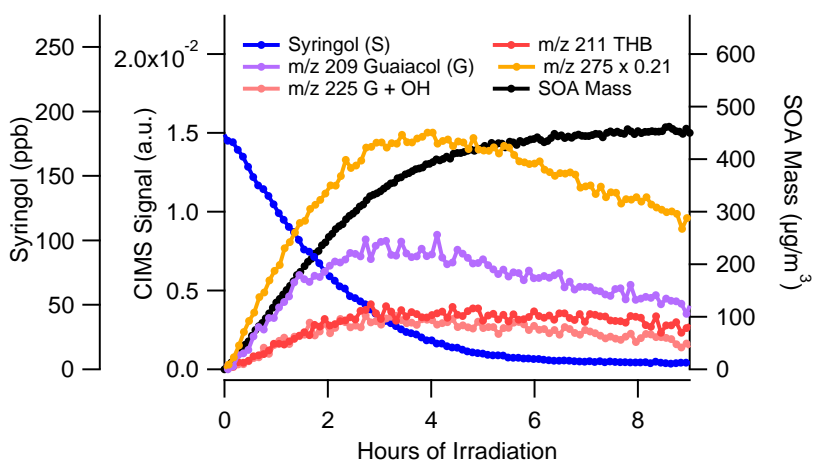

Fig. 7. Selected traces in syringol low- $\mathrm{NO}_{\mathrm{x}}$ gas-phase and particlephase development. (A) OH addition pathways. (B) Traces indicating methoxy loss pathways.

shown. Though a guaiacol channel exists, the coincident formation of $m / z 225(\mathrm{G}+\mathrm{OH})$ and $\mathrm{m} / \mathrm{z} 211$ (THB) with that of guaiacol at $m / z, 209$ is consistent with their direct formation from syringol $+\mathrm{OH}$.

\subsection{Novel chemical pathways for loss of carbon in methoxyphenol systems}

We observe evidence that guaiacol and syringol $\mathrm{OH}$-initiated photooxidation leads to loss of carbon, likely due to unique chemistry involving the methoxy group. While gas-phase aromatic chemistry is not completely understood (Calvert et al., 2002), we propose possible explanations for these carbon loss pathways. Carbon loss from aromatic systems has been observed previously in the gas-phase, and is thought to be a result of ipso addition of $\mathrm{OH}$ at a substituent containing ring carbon and subsequent elimination of the substituent leaving a phenolic group. This is the case for alkylbenzenes, in which Noda et al. (2009) observed phenol formation from $\mathrm{OH}$-initiated photooxidation of toluene and cresol formation from xylenes. Prior, Koch et al. (2007) provided evidence that the ipso addition of $\mathrm{OH}$ is relevant for the case of hexamethylbenzene. The extent by which these processes occur in the gas-phase is still unclear, as Aschmann et al. (2010) does not observe the dealkylation as in Noda et al. (2009). Addition at the ipso position is generally considered to be a minor route ( $\leq 20 \%$ for the alkylbenzenes studied in Noda et al., 2009), though it could be that oxy substituents may influence the favorability of this route. Raff and Hites (2006) found that brominated diphenylethers also undergo ether cleavage, proposed as a result of ipso addition of $\mathrm{OH}$. Thus, ipso addition of $\mathrm{OH}$ in the gas-phase may be more relevant for more highly-substituted and/or more complex substitutents on aromatics.

Koch et al. (2007) also pointed out several liquid-phase studies that find evidence of ether bond cleavage. Again, ipso addition of hydroxyl radical is cited as being responsible for ether bond cleavage (removal of an oxy substitutent) and $\mathrm{C}$ C cleavage (removal of a methyl substituent) in some cases. Aihara et al. (1993) studied two pathways in which 1,2dihydroxybenzene (catechol) forms from $o$-methoxyphenols using a copper (II) - ascorbic acid-dioxygen system: hydroxyl radical attack ipso to the methoxy containing carbon, and $\mathrm{H}$-abstraction from the methoxy group. Hydroxy radical attack ipso to the methoxy containing carbon allows for loss of the methoxy $\left(-\mathrm{OCH}_{3}\right)$ group in the form of methanol $\left(\mathrm{CH}_{3} \mathrm{OH}\right)$, removing a $\mathrm{C}$ atom from the parent molecule. During $\mathrm{H}$-abstraction from the methoxy group, Aihara et al. (1993) propose that the $\mathrm{OCH}_{2}$ radical reacts with the $\mathrm{OH}$ radical and then elimination of formaldehyde (HCHO) ensues. In isotopically labeled studies, Aihara et al. (1993) observed transformation of guaiacol to catechol and syringol to hydroxy guaiacol. They also measure yields of these products that might imply ipso addition of $\mathrm{OH}$ being a more important route than previously considered compared to ortho- and para-OH addition to the ring. This route could serve as explanation of the observed hydroxy substitutions of methoxy groups in the current systems, but they cannot be verified without measurements of methanol and formaldehyde.

While we see ions indicating that methoxy groups may convert to hydroxyl groups, we do not see evidence supporting the addition of or reversible exchange of methoxy groups to the ring. Methoxy radicals may be formed from photolysis of the $\mathrm{C}-\mathrm{OCH}_{3}$ bond, if we assume that this bond energy can be proxied by the bond in dimethylether $\left(\mathrm{CH}_{3}-\mathrm{OCH}_{3}\right)$. This bond energy, $351.9 \mathrm{~kJ} \mathrm{~mole}^{-1}$ (Luo, 2007), translates to an approximate wavelength of $340 \mathrm{~nm}$, exactly where the irradiance spectrum of the light source in our atmospheric chambers peaks. In the event that methoxy radicals are formed, though, it seems unlikely that methoxy radical reaction with the methoxyphenols results in methoxy addition to the ring or replacement of a hydroxy group, especially compared to rapid reaction with $\mathrm{O}_{2}$. Gomez et al. (2001) studied the reaction rate constants for methoxy radical with cyclohexane, cyclohexene, and 1,4-cyclohexadiene. It was found that methoxy radical reaction with these compounds is likely to result in preferential $\mathrm{H}$ abstraction with minor routes of addition to cyclohexene and 1,4-cyclohexadiene. This corroborates the absence of $>\mathrm{C}_{7}$ species in the guaiacol case and $>\mathrm{C}_{8}$ species in the syringol case. 

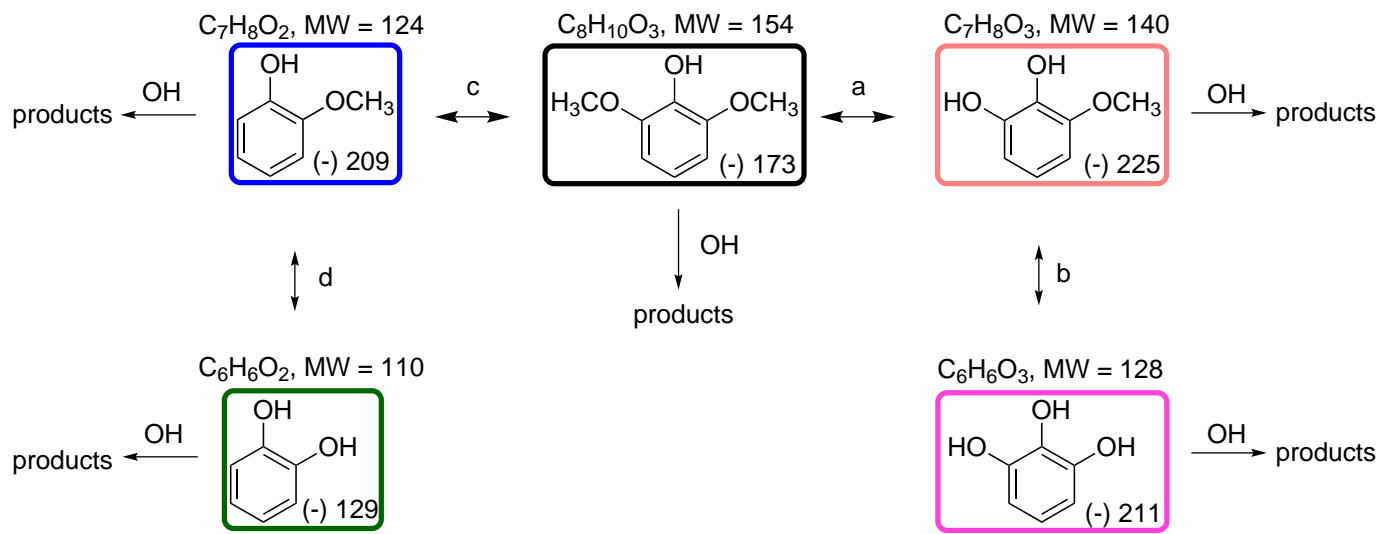

Fig. 8. Possible routes of methoxy loss in syringol gas-phase chemistry.

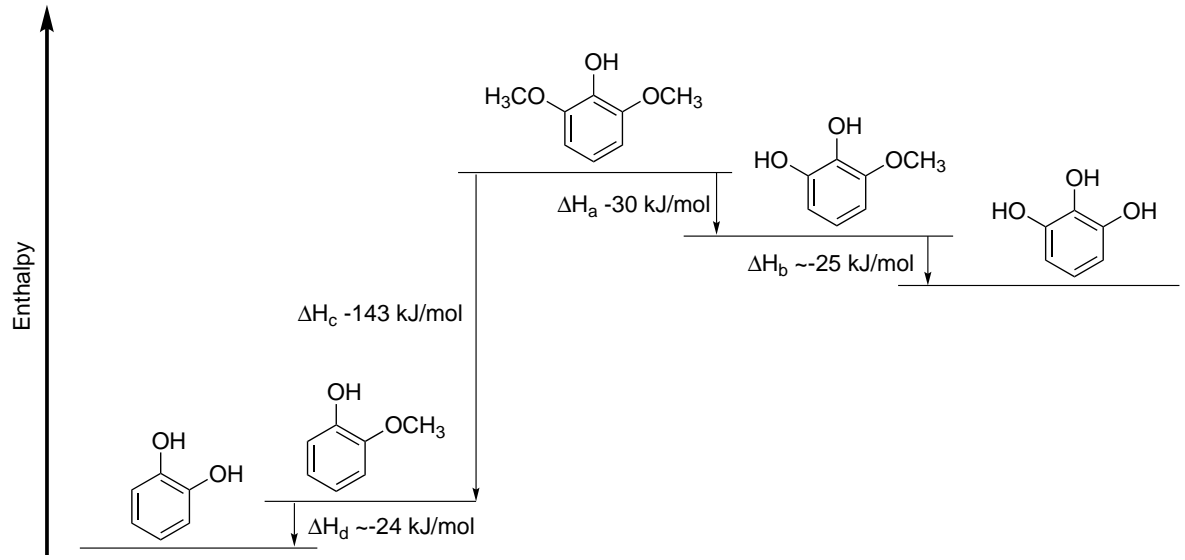

Fig. 9. Estimates of enthalpy differences between several products indicating methoxy loss.

Thermodynamic evaluation of the substituent group effects in methoxyphenols can also provide some insight. The following discussion is based on the work presented in Varfolomeev et al. (2010) that examines pairwise substitution effects, and inter- and intramolecular hydrogen bonds in methoxyphenols and dimethoxybenzenes. Varfolomeev et al. (2010) show that intramolecular hydrogen bonding plays a significant role on ortho-methoxy substituted phenols. This leads to $o$-methoxyphenols having a lower phenolic $\mathrm{O}-\mathrm{H}$ bond dissociation energy (BDE) compared to meta isomers and higher than para isomers. This means that the phenolic O-H BDE increases in order the order 4-methoxyphenol $<2$-methoxyphenol $<3$-methoxyphenol. From the ab initio calculations of Varfolomeev et al. (2010), the enthalpy of formation for 2-methoxyphenol (guaiacol) is expressed below:

$$
\begin{aligned}
& \Delta_{\mathrm{f}} H_{m}^{\circ}(2 \text {-methoxyphenol })=\Delta_{\mathrm{f}} H_{m}^{\circ}(\mathrm{B})+\Delta H(\mathrm{H} \rightarrow \mathrm{OH}) \\
& \quad+\Delta H\left(\mathrm{H} \rightarrow \mathrm{OCH}_{3}\right)+(\text { ortho-OH-OCH})
\end{aligned}
$$

where $\Delta_{\mathrm{f}} H_{m}^{\circ}(\mathrm{B})=$ enthalpy of formation of benzene, $\Delta H(\mathrm{H} \rightarrow \mathrm{OH})=-179.0 \mathrm{~kJ} \mathrm{~mol}^{-1}$, the increment in enthalpy for substitution of an $\mathrm{H}$ atom by $-\mathrm{OH}, \Delta H(\mathrm{H} \rightarrow$
$\left.\mathrm{OCH}_{3}\right)=-150.5 \mathrm{~kJ} \mathrm{~mol}^{-1}$, the increment in enthalpy for substitution of an $\mathrm{H}$ atom by $-\mathrm{OCH}_{3}$, and (ortho$\left.\mathrm{OH}-\mathrm{OCH}_{3}\right)=4.5 \mathrm{~kJ} \mathrm{~mol}^{-1}$, the increment in enthalpy for the pairwise interactions of $-\mathrm{OH}$ and $-\mathrm{OCH}_{3}$ ortho to one another.

The enthalpy of formation expression begins with the base enthalpy of formation from benzene, then adds the effects of hydroxy or methoxy substitution to the ring. Finally, the pairwise interactions are added, reflecting the stabilizing intramolecular $\mathrm{H}$ bonding and destabilizing effect from sterics in the ortho- $\mathrm{OH}-\mathrm{OCH}_{3}$ configuration. From the comparison of the substitution effects alone, this suggests that $\mathrm{H} \rightarrow \mathrm{OH}$ is slightly more favorable than $\mathrm{H} \rightarrow \mathrm{OCH}_{3}$. For example, this might support substitution of a methoxy group by a hydroxy group in the guaiacol system, as the pairwise ortho effect is minimal.

Assuming that the Varfolomeev et al. (2010) formulation can be extended to the case of a trisubstituted benzene, we can write an analogous expression for the case of syringol (2,6-dimethoxyphenol): 


$$
\begin{aligned}
& \Delta_{\mathrm{f}} H_{m}^{\circ}(2,6 \text {-dimethoxyphenol })=\Delta_{\mathrm{f}} H_{m}^{\circ}(\mathrm{B})+\Delta H(\mathrm{H} \rightarrow \mathrm{OH}) \\
& \quad+2 \times \Delta H\left(\mathrm{H} \rightarrow \mathrm{OCH}_{3}\right)+2 \times(\text { ortho-OH-OCH } \\
& \\
& \quad+\left(\text { meta }-\mathrm{OCH}_{3}-\mathrm{OCH}_{3}\right),
\end{aligned}
$$

where $\left(\right.$ meta $\left.-\mathrm{OCH}_{3}-\mathrm{OCH}_{3}\right)=0.1 \mathrm{~kJ} \mathrm{~mol}^{-1}$ from Varfolomeev et al. (2010).

After writing a similar expression for 3-methoxybenzene1,2-diol (hydroxyguaiacol), the difference between the substituent effects for hydroxyguaiacol and syringol is $-30 \mathrm{~kJ} \mathrm{~mol}^{-1}$, in slight favor of hydroxyguaiacol. The pairwise effect of (ortho-OH-OH) was not calculated by Varfolomeev et al. (2010), but assuming that it is less sterically hindered compared to (ortho- $\mathrm{OH}-\mathrm{OCH}_{3}$ ) and is stabilized by intramolecular hydrogen bonding similar to 1,2dimethoxybenzene, we assume it to be $<4.5 \mathrm{~kJ} \mathrm{~mol}^{-1}$. Due to the combined favorability of energetics for the substituent effects and the pairwise effects, this can help explain why some of the syringol rapidly converts to hydroxyguaiacol and even trihydroxybenzene. A simplified schematic with estimated enthalpy differences using this analysis is presented in Fig. 9.

The "phenolic route", involving $\mathrm{OH}$ addition at the ortho position to the main electron-donating substituent group has been cited as being the main channel responsible for SOA formation in many aromatic systems (Calvert et al., 2002; Johnson et al., 2005; Nakao et al., 2011). However, with the additional methoxy groups, $\mathrm{OH}$ attack at the alphaunsubstituted carbons to the methoxy groups becomes competitive and changes the potential for maintaining aromaticity in the methoxyphenol systems. It is possible that the extra methoxy group in syringol inhibits $\mathrm{OH}$ attack that is typically favored ortho to the hydroxyl substituted carbon in other systems that generate SOA via this route. For the other compounds, in order to achieve the degree of oxidation of the aerosol, it appears that at least two steps of reaction are needed, but that these steps occur fairly rapidly. If subsequent $\mathrm{OH}$ reactions are even slower due to the extra methoxy group in the case of syringol, then conversion to SOA may not be as complete as with the other two compounds over the duration of the experiments reported here.

\subsection{Chemical basis for observed yields}

The AMS high-resolution spectra for the methoxyphenol systems are distinct. Initial aerosol growth in the guaiacol system is marked by the exact mass ion $\mathrm{C}_{4} \mathrm{H}_{3} \mathrm{O}_{2}^{+}$. Later the aerosol growth is characterized by the ions $\mathrm{C}_{2} \mathrm{H}_{3} \mathrm{O}^{+}$, and $\mathrm{C}_{2} \mathrm{H}_{5} \mathrm{O}_{2}^{+}$. In the case of syringol, initial growth is characterized by $\mathrm{C}_{5} \mathrm{H}_{2} \mathrm{O}_{2}^{+}$and $\mathrm{C}_{7} \mathrm{H}_{9} \mathrm{O}_{3}^{+}$ions, followed by $\mathrm{C}_{5} \mathrm{H}_{5} \mathrm{O}_{4}^{+}$, and then by $\mathrm{C}_{5} \mathrm{H}_{2} \mathrm{O}_{4}^{+}$and $\mathrm{C}_{2} \mathrm{H}_{4} \mathrm{O}_{3}^{+}$. This suggests that guaiacol SOA is characterized by smaller carbon number and less oxygenated fragments than the case of syringol.

The characteristic ions from the AMS spectra for syringol SOA seem counter-intuitive for understanding why the sy- ringol SOA yield is lower than that of guaiacol. Syringol has more carbon and oxygen to begin with and these ions are larger, more oxygenated fragments than in guaiacol. However, if we return to the gas-phase comparison of the characteristic trends in the guaiacol (Fig. 5) and syringol (Fig. 7) systems, one notes that many of the major products from syringol photooxidation peak later than their analogs in the guaiacol system. Further, there is no analogous peak in the guaiacol system to the $\mathrm{m} / \mathrm{z}, 275$ unique to the syringol system. Since this is a major product of gas-phase syringol photooxidation and it peaks $>4 \times 10^{6} \mathrm{molec} \mathrm{cm}^{-3} \mathrm{~h}$ of OH exposure compared to guaiacol ions that peak generally within $3 \times 10^{6}$ molec $\mathrm{cm}^{-3} \mathrm{~h}$, it acts like a gas-phase carbon reservoir. That is, the signal at $m / z, 275$ is much more significant than the more efficient SOA formers at $\mathrm{m} / \mathrm{z}, 129$ (dihydroxybenzene, not shown) and $m / z 209$ (guaiacol) in Fig. 7b.

AMS elemental analyses of SOA from these systems as reported in Chhabra et al. (2011) suggest that the majority of oxygenation is derived from organic acid functionalities: $77 \%$ for phenol, $61 \%$ for guaiacol, and $59 \%$ for syringol. This is consistent with the necessity of further oxidation of ring-opened dicarbonyl fragments and ring-opened acids to explain the presence of highly oxidized species observed in the guaiacol filter analyses. Ofner et al. (2010) found that the SOA-formation process from catechol involves ring-opened carboxylic acid derivatives that are part of highly hydroxylated olefin structures, which supports the organic acid functionality observed in the current related systems. Previous study on the ozonolysis of 1,2-dihydroxybenzene showed that several carbonyls existed in both the gas and particle phases (Olariu, 2001). Carboxylic acids believed to be ring fragments, as well as muconic acid, a ring-opened $\mathrm{C}_{6}$ dicarboxylic acid, were also identified. Muconic acid was also identified in the particle phase from benzenediol ozonolysis (Tomas et al., 2003). These results support the current observations that many dicarbonyl species in general trend with the SOA mass, suggesting that they may be semi-volatile in nature.

The decrease in oxygenation derived from organic acid functionalities from phenol to the methoxyphenol systems may reflect the oxygen reserved in $\mathrm{OH}$ adduct and aromatic retaining pathways, especially in the case of syringol (Fig. 8). This may also partially explain why the syringol SOA yield is lower if particle-phase acid formation from carbonyl ring fragments drives the SOA growth. At similar $\mathrm{OH}$ exposures, the syringol system still has not developed a carbonyl ring fragment signal that tracks well with the SOA growth, as $\mathrm{m} / \mathrm{z} 185$ does in the phenol system (Fig. 2) and $\mathrm{m} / \mathrm{z} 149$ does in the guaiacol system (Fig. 5). The $m / z 245$ fragment lags the SOA growth in the syringol system (Fig. 7a). This could be due to the lack of $\mathrm{OH}$ addition to the ring on syringol in critical positions that lead to SOA formation via ring-fragmentation pathways and acid formation.

Estimation of carbon oxidation state also provides some insight into the chemical evolution of the aerosol towards 
incorporation of highly oxidized species. Representative time series of the carbon oxidation state, $\overline{\mathrm{OS}}_{\mathrm{c}}$, for the studied systems are shown in Fig. 10. Carbon oxidation state was estimated with the AMS O: $\mathrm{C}$ and $\mathrm{H}: \mathrm{C}$ elemental analyses using the formulation presented in Kroll et al. (2011). All systems approach an $\overline{\mathrm{OS}}_{\mathrm{c}}$ of +0.5 . This approaches the range of low-volatility oxygenated organic aerosol (Kroll et al., 2011). A delay in the rise of $\overline{\mathrm{OS}}_{\mathrm{c}}$ from phenol aerosol is observed, consistent with the rise in organic growth at the point of formation of trihydroxybenzene (Fig. 2). Syringol aerosol lags in oxidation in the beginning compared to guaiacol until approximately $4 \times 10^{6}$ molec $\mathrm{cm}^{-3} \mathrm{~h}$ of $\mathrm{OH}$ exposure. This times with the peak of many of the methoxy loss products in Fig. $7 b$, supporting that additional oxidation is achieved once methoxy loss occurs and the syringol product distribution overlaps that of guaiacol (i.e. $\mathrm{G}+\mathrm{OH}$ and THB) and the "phenolic route". Primary organic aerosol from biomass burning was found to have an $\overline{\mathrm{OS}}_{\mathrm{c}}$ of -1.0 to -0.7 (Aiken et al., 2008; Kroll et al., 2011), which falls inbetween the range of $\overline{\mathrm{OS}}_{\mathrm{c}}$ from the three systems here. However, aged (Whistler Mountain) aerosols ranged -0.6 to +0.6 (Sun et al., 2009; Kroll et al., 2011), enveloping the methoxyphenols and a portion of the phenol $\overline{\mathrm{OS}}_{\mathrm{c}}$ evolution. In terms of average carbon oxidation state, these experiments pick up from primary organic aerosol in biomass burning and move towards the character of aged organic aerosol.

\section{Atmospheric relevance}

While the current experiments were conducted without the addition of $\mathrm{NO}_{\mathrm{x}}$, the chemistry elucidated under these low$\mathrm{NO}_{\mathrm{x}}$ conditions is expected to be relevant for typical atmospheric conditions. For phenol photooxidation in the presence of $\mathrm{NO}_{\mathrm{x}}$, Olariu et al. (2002) measured yields of 0.8 catechol (1,2-dihydroxybenzene), 0.037 1,4-benzoquinone, and 0.058 2-nitrophenol. However, according to kinetic data and yield comparisons for nitrophenol presented in Berndt and Boge (2003), it is likely that this nitro-product formation can be biased due to sufficiently high $\mathrm{NO}_{2}(\lesssim 800 \mathrm{ppb})$ concentrations. Berndt and Boge (2003) point out that for atmospheric conditions with $\mathrm{NO}_{2}$ of approximately $20 \mathrm{ppb}$, it is probable that phenoxy radicals also react with $\mathrm{O}_{3}$ as well as $\mathrm{NO}$ and $\mathrm{NO}_{2}$. This would result in more minor nitrophenol yields in the atmosphere for daytime chemistry. Reaction with $\mathrm{NO}_{3}$ should also be considered as phenolic compounds can react rapidly with trace levels of $\mathrm{NO}_{3}$ during the day and especially at night.

Thus, because $\mathrm{OH}$ addition dominates over $\mathrm{H}$ abstraction, and subsequent $\mathrm{O}_{2}$ addition to the $\mathrm{OH}$ radical adduct is rapid, it is more likely that in the atmosphere, SOA primarily forms via pathways involving higher-generation $\mathrm{OH}$ adducts and their respective routes to oxygenated fragments. This is consistent with the chemistry presented in this work. Though we did not observe appreciable evidence of gas-phase hydroper-

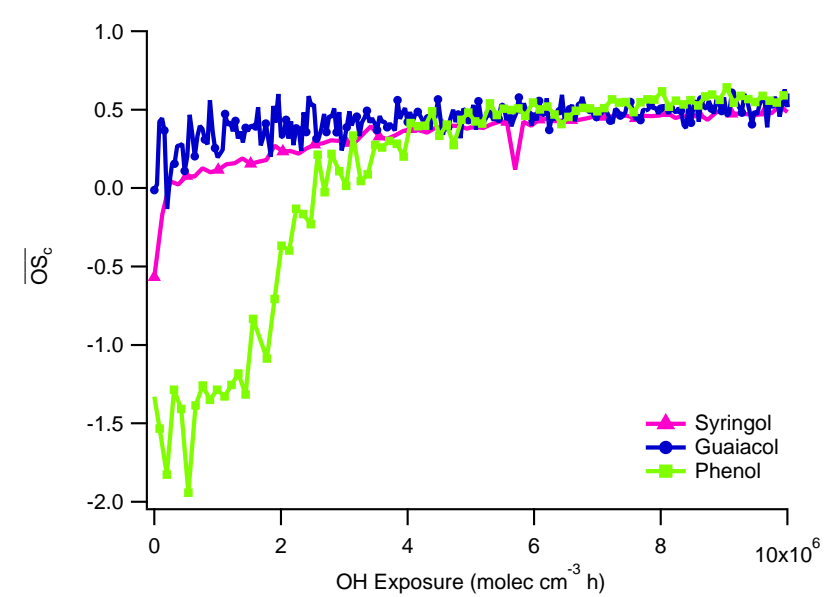

Fig. 10. Evolution of the average carbon oxidation state $\left(\overline{\mathrm{OS}}_{\mathrm{c}}\right)$ for studied systems.

oxides, they may be rapidly incorporated into the particle phase and contribute to peroxide formation, as postulated by Johnson et al. (2005) and observed by Sato et al. (2007) for the case of toluene photooxidation. Sato et al. (2007) also find similar species in the particle-phase under $[\mathrm{NO}]_{0}=0.2$ and $1 \mathrm{ppm}$, still citing $\mathrm{O}_{2}$ addition to the $\mathrm{OH}$-aromatic adduct as the major channel contributing to SOA formation.

In the presence of moderate $\mathrm{NO}_{\mathrm{x}}$, we would expect the major gas-phase species to be the same as those presented here, with only a minor contribution from nitrogen-containing products. Still, for the studied compounds, novel routes of reaction of alkylperoxy radicals under these low- $\mathrm{NO}_{\mathrm{x}}$ conditions may still result in product distributions expected under higher $\mathrm{NO}_{\mathrm{x}}$ conditions. First, the aromatic peroxy radicals in the studied systems may preferentially decompose to regenerate $\mathrm{OH}$ via novel $\mathrm{RO}_{2}+\mathrm{HO}_{2}$ chemistry (Birdsall et al., 2010). This is a possible explanation for the observation of ring-opened acids in phenol and guaiacol. Second, generation of carbonyls via novel rearrangements of ether peroxy radicals (Orlando and Tyndall, 2012), relevant for guaiacol and syringol, would further make the product distributions less distinct from alkoxy radical pathways expected under high- $\mathrm{NO}_{\mathrm{x}}$ chemistry.

These observations warrant caution when conducting experiments in the presence of $\mathrm{NO}_{\mathrm{x}}$ for aromatic compounds, as derived aerosol yields may be based on chemistry nonrepresentative of the atmosphere. Hence, we left discussion of the experiments conducted in the presence of $\mathrm{NO}_{\mathrm{x}}$ for the Appendix. Klotz et al. (2002) found that at high- $\mathrm{NO}_{\mathrm{x}}$ conditions (hundreds of ppb to ppm) one must also start to consider reactions of $\mathrm{NO}_{\mathrm{x}}$ with the hydroxy radical adduct. At sufficiently high $\mathrm{NO}_{\mathrm{x}}$ concentrations, the gas-phase chemistry can generate higher yields of nitroaromatics as compared to the $\mathrm{OH}$ aromatic adduct (Koch et al., 2007; Nishino et al., 2008). Nitroaromatics can serve to enhance aerosol yields if sufficient nitro-containing functionalities are achieved or 
to act as gas-phase carbon reservoirs and depress aerosol yields. Hydroxyl groups will lead to a vapor pressure lowering more than that associated with nitro groups, but sufficient nitro groups could lead to incorporation to the particle phase. Owing to the lower $\mathrm{OH}$ reactivity of the molecule containing a nitro group as compared to the comparable molecule containing a hydroxyl group (Kwok and Atkinson, 1995), one might also find that more $\mathrm{OH}$ is necessary in the presence of $\mathrm{NO}_{\mathrm{x}}$ to attain further gas-phase development to more highly oxidized species that contribute to SOA formation.

While the $\mathrm{OH}$-initiated photooxidation of aromatics in general is complex (Calvert et al., 2002), methoxyphenols seem to follow some steps of the general mechanism developed for simpler aromatics. We have qualitatively presented gas-phase trends that give some insight into the chemistry of SOA formation. Though, more complete mechanism development would be enhanced by the availability of authentic standards to solidify mass assignments and more detailed structural information. For example, the structural identity of the ion at $m / z 275$ in the syringol system remains elusive. Calculation of quantitative gas-phase yields would benefit from additional kinetic data pertaining to some of the complex intermediates.

Carbon loss via the methoxy groups in guaiacol and syringol appears to be a feasible route to describe the gasphase product distributions. While the chemistry of syringol is complex, this compound may be a better model system to represent the mixture of methoxy and phenolic compounds since it displays chemistry from both classes. Syringol, however, does not generate as much SOA as these other systems. This may be a result of the unique $\mathrm{OCH}_{3}-\mathrm{OH}-\mathrm{OCH}_{3}$ pairwise effects that hinder the typical phenolic pathway responsible for SOA formation.

Future studies to investigate this effect might start with methoxyphenols of different substituted positions relative to the hydroxy group to see the effect on SOA yields. For example, using a methoxyphenol where at least one or two methoxy groups are not ortho to the hydroxy group would serve to further investigate the importance of $\mathrm{OH}$ addition ortho to the hydroxy group in these compounds, as 1,2dihydroxybenzene is the major gas-phase product and SOA former from phenol. Also, 2,5-dimethoxyphenol might also indicate if $\mathrm{OH}$ attack is preferred at the 6-position, again ortho to the hydroxy group. Such studies would require more detailed analyses that provide greater structural analysis for the gas-phase products as well as unique tracers for fragmentation patterns that would clarify the chemistry.

Detailed study of the gas-phase products from the $\mathrm{OH}$ initiated photooxidation of methoxybenzene might also be informative for understanding the proposed carbon loss associated with methoxy groups in the guaiacol and syringol systems. If phenol is a major product, this has implications on understanding the chemical fate of methoxyphenol-like compounds in the atmosphere. For example, Lauraguais et al. (2012) suggest that syringol is too reactive with $\mathrm{OH}(1.8 \mathrm{~h})$ to be a relevant tracer in the atmosphere for woodsmoke emissions and that it results in a very minor SOA yield. However, the chemical analyses presented in this study suggest that syringol can efficiently convert to guaiacol and hydroxylated benzenes that are longer lived in the atmosphere and potentially have larger SOA yields. This can be analogous to the isoprene photochemical cascade, where it is the products of isoprene photooxidation that have greater SOA forming potential (Kroll et al., 2006). The syringol conversion to guaiacol also has implications for using these compounds as specific tracers for fuel type (hardwood vs. softwood). Thus, care must be taken in selecting one or more surrogate species for use in modeling aerosol yields from biomass burning emissions in the atmosphere.

\section{Appendix A}

\section{Methoxyphenol oxidation in the presence of $\mathrm{NO}_{\mathrm{x}}$}

We present here results from the methoxyphenol experiments performed in the presence of $\mathrm{NO}_{\mathrm{x}}$ including SOA yields and qualitative analyses of the chemical development in these systems. As mentioned in the Introduction section, the main text of this paper focuses on methoxyphenol and phenol photooxidation under idealized chemical conditions $\left(\mathrm{NO}_{\mathrm{x}}<10 \mathrm{ppb}\right)$, such that the predominant fate of the $\mathrm{RO}_{2}$ radical here is reaction with $\mathrm{HO}_{2}$. Biomass burning events certainly generate $\mathrm{NO}_{\mathrm{x}}$, and the authors recognize that the low- $\mathrm{NO}_{\mathrm{x}}$ chemistry presented in the main text by no means provides the complete chemical picture of aged biomass burning plumes. A complementary set of experiments in the presence of $\mathrm{NO}_{\mathrm{x}}$ was conducted along with the low- $\mathrm{NO}_{\mathrm{x}}$ experiments presented earlier using the same protocols, except that $\mathrm{HONO}$ was used as the $\mathrm{OH}$ precursor instead of $\mathrm{H}_{2} \mathrm{O}_{2}$ and NO was also injected.

However, we do not focus on the results of these experiments in the main text for both technical and scientific reasons including: (1) The actual experimental conditions resulted in hundreds of ppb levels of $\mathrm{NO}_{\mathrm{x}}$, which are much higher than those reported for biomass burning events. For example, linuma et al. (2010) measured biomass burning co-located $\mathrm{NO}_{\mathrm{x}}$ on the order of $20 \mathrm{ppb}$. Thus, the product distributions in these experiments result in favored nitroproducts, but do not necessarily represent the more relevant chemical development in the atmosphere. $\mathrm{NO}_{\mathrm{x}}$ levels can also become depleted several hours later (via $\mathrm{NO}_{2}$ incorporation into PAN species) or with dilution via transport of a plume as observed in Akagi et al. (2012). Thus, experiments in the absence of or at levels of $\mathrm{NO}_{\mathrm{x}}<10 \mathrm{ppb}$ (such as those presented in the main text) can still be representative of product distributions at lower $\mathrm{NO}_{\mathrm{x}}$ levels $(<30 \mathrm{ppb})$ when methoxyphenol precursors are transported away and subsequently photooxidize. (2) Interference of HONO response on our $\mathrm{NO}_{\mathrm{x}}$ analyzer made it more difficult to report 
Table A1. Experimental conditions and aerosol yields in the presence of added $\mathrm{NO}_{\mathrm{x}}$.

\begin{tabular}{|c|c|c|c|c|c|c|c|c|c|}
\hline $\begin{array}{l}\text { Date } \\
(2010)\end{array}$ & Organic & $\begin{array}{c}{[\mathrm{Org}]_{0}} \\
(\mathrm{ppb})\end{array}$ & $\begin{array}{c}{[\mathrm{Org}]_{\mathrm{f}}} \\
(\mathrm{ppb})\end{array}$ & $\begin{array}{l}\mathrm{RH}_{0} \\
(\%)\end{array}$ & $\begin{array}{c}{\left[\mathrm{NO}_{2}\right]_{0}{ }^{\mathrm{a}}} \\
(\mathrm{ppb})\end{array}$ & $\begin{array}{c}{[\mathrm{NO}]_{0}^{\mathrm{a}}} \\
(\mathrm{ppb})\end{array}$ & $\begin{array}{c}\mathrm{Vol}_{0}^{\mathrm{b}} \\
\mu \mathrm{m}^{3} \mathrm{~cm}^{-3}\end{array}$ & $\begin{array}{c}\mathrm{Vol}_{\mathrm{f}}^{\mathrm{b}} \\
\mu \mathrm{m}^{3} \mathrm{~cm}^{-3}\end{array}$ & Yield \\
\hline $2 / 3$ & guaiacol & 14.2 & 0.7 & $<\mathrm{LDL}^{\mathrm{c}}$ & 447 & 282 & 12.9 & 27.5 & $0.34 \pm 0.02$ \\
\hline $2 / 5$ & guaiacol & 51.9 & 3.1 & 5.6 & 536 & 461 & 13.5 & 92.5 & $0.53 \pm 0.01$ \\
\hline $3 / 2$ & guaiacol & 38.0 & 2.0 & $<\mathrm{LDL}^{\mathrm{c}}$ & 458 & 295 & 10.5 & 65.4 & $0.46 \pm 0.01$ \\
\hline $3 / 28$ & guaiacol & 13.6 & 0.8 & $<\mathrm{LDL}^{\mathrm{c}}$ & 429 & 222 & 11.4 & 26.5 & $0.35 \pm 0.02$ \\
\hline $3 / 31$ & guaiacol & 55.3 & 4.0 & $<\mathrm{LDL}^{\mathrm{c}}$ & 518 & 330 & 13.8 & 86.5 & $0.46 \pm 0.02$ \\
\hline $4 / 6$ & guaiacol & 16.4 & 1.2 & $<\mathrm{LDL}^{\mathrm{c}}$ & 493 & 314 & 9.0 & 29.4 & $0.4 \pm 0.02$ \\
\hline $4 / 9^{d}$ & guaiacol & 14.2 & 0.5 & $<\mathrm{LDL}^{\mathrm{c}}$ & 509 & 315 & 18.7 & 33.5 & $0.35 \pm 0.02$ \\
\hline $4 / 13^{\mathrm{d}}$ & guaiacol & 15.4 & 0.8 & $<\mathrm{LDL}^{\mathrm{c}}$ & 464 & 296 & 11.3 & 27.1 & $0.4 \pm 0.02$ \\
\hline $4 / 15$ & guaiacol & 35.6 & 3.7 & $<\mathrm{LDL}^{\mathrm{c}}$ & 526 & 321 & 10.8 & 55.7 & $0.49 \pm 0.02$ \\
\hline $4 / 22$ & guaiacol & 50.4 & 4.4 & $<\mathrm{LDL}^{\mathrm{c}}$ & 433 & 329 & 14.4 & 74.6 & $0.47 \pm 0.02$ \\
\hline $2 / 19$ & phenol & 14.8 & 1.9 & $<\mathrm{LDL}^{\mathrm{c}}$ & 443 & 295 & 14.0 & 32.0 & $0.54 \pm 0.06$ \\
\hline $3 / 23$ & phenol & 23.5 & 3.0 & $<\mathrm{LDL}^{\mathrm{c}}$ & 488 & 301 & 14.2 & 37.9 & $0.54 \pm 0.06$ \\
\hline $3 / 6$ & syringol & 53.1 & 2.4 & $<\mathrm{LDL}^{\mathrm{c}}$ & 448 & 286 & 11.9 & 68.0 & $0.3 \pm 0.01$ \\
\hline $3 / 9$ & syringol & 124.2 & 4.2 & $<\mathrm{LDL}^{\mathrm{c}}$ & 481 & 313 & 14.6 & 110.0 & $0.2 \pm 0.01$ \\
\hline $3 / 11$ & syringol & 92.3 & 2.9 & $<\mathrm{LDL}^{\mathrm{c}}$ & 469 & 314 & 12.6 & 73.0 & $0.17 \pm 0.01$ \\
\hline $3 / 13$ & syringol & 31.9 & 1.0 & $<\mathrm{LDL}^{\mathrm{c}}$ & 418 & 241 & 12.8 & 29.0 & $0.11 \pm 0.01$ \\
\hline
\end{tabular}

a Corrections for HONO interference not made; values for $\mathrm{NO}_{\mathrm{x}}$ listed are upper limits

${ }^{\mathrm{b}} \mathrm{Vol}_{0}$ is initial seed volume; $\mathrm{Vol}_{\mathrm{f}}$ is final volume (seed + organic aerosol), as measured by DMA

c $\mathrm{RH}$ probe $\mathrm{LDL}=5 \% \mathrm{RH}$

$\mathrm{d}$ Additional HONO injected mid-experiment

precise $\mathrm{NO}_{\mathrm{x}}$ levels. (3) Before photooxidation commenced, we observed a likely nitro-product that formed once HONO was introduced to the reactors, presumably a reaction of methoxyphenol with $\mathrm{HONO}$ and/or $\mathrm{NO}_{\mathrm{x}}$ (by-product of the HONO synthesis) in the dark to form a nitro-product. This was not observed in Lauraguais et al. (2012) for the case of syringol and $\mathrm{CH}_{3} \mathrm{ONO}$ in the dark. While direct $\mathrm{HONO} / \mathrm{NO}_{\mathrm{x}}$ reaction with the methoxyphenol compounds may be of atmospheric relevance, this complicated the chemical system that we started with and made it difficult to constrain the chemistry for the observed product distributions.

\section{A1 Methoxyphenol SOA yields in the presence of $\mathrm{NO}_{\mathrm{x}}$}

The yield data presented here are not recommended for use in atmospheric models, as the conditions of the experiments are not representative of typical or biomass burning $\mathrm{NO}_{\mathrm{x}}$ levels in the atmosphere. The excess of $\mathrm{NO}_{\mathrm{x}}$ employed in these experiments likely biases the product distributions to more nitrogen-containing species, thereby affecting associated volatilities and the SOA yields. All experiment conditions and SOA yields are presented in Table A1.

For high- $\mathrm{NO}_{\mathrm{x}}$ experiments ( $\mathrm{NO}>200 \mathrm{ppb}$ initially), nitrous acid (HONO) was used as the $\mathrm{OH}$ precursor. $\mathrm{HONO}$ was prepared by adding $15 \mathrm{~mL}$ of $1 \mathrm{wt} \%$ aqueous $\mathrm{NaNO}_{2}$ dropwise into $30 \mathrm{~mL}$ of $10 \mathrm{wt} \%$ sulfuric acid in a glass bulb. A stream of dry air was then passed through the bulb, sending $\mathrm{HONO}$ into the chamber. During this process $\mathrm{NO}$ and $\mathrm{NO}_{2}$ formed as side products and were also introduced into the chamber. $\mathrm{NO} / \mathrm{NO}_{\mathrm{x}}$ was measured with a commercial chemiluminescence $\mathrm{NO}_{\mathrm{x}}$ monitor (Horiba, APNA-360) with lower detection limit (LDL) of $5 \mathrm{ppb}$ of NO. Total starting $\mathrm{NO}_{\mathrm{x}}$ was generally just under $800 \mathrm{ppb}$ as indicated by the $\mathrm{NO}_{\mathrm{x}}$ analyzer, and no corrections have been made for HONO interference on the analyzer.

Additional $\mathrm{HONO}$ was injected in two $\sim 14 \mathrm{ppb}$ guaiacol experiments (4/9 and 4/13) to explore the extent to which additional $\mathrm{OH}$ and $\mathrm{NO}_{\mathrm{x}}$ would affect the gas-phase chemistry leading to SOA formation. Additional HONO was injected both at the mid-point of aerosol growth (4/13) and at the point where virtually all of the initial organic had been consumed (4/9). In both cases, further oxidation by $\mathrm{OH}$ did not lead to further aerosol formation in comparison to the guaiacol high- $\mathrm{NO}_{\mathrm{x}}$ experiment with similar organic loading (2/3). While an enhancement of some nitrogen-containing products occurred as observed in the gas phase for the cases with additional HONO (4/9 and 4/13), this suggests that the major components of SOA formation are not likely from these particular products. In addition, there were no observations of new species in the CIMS spectra to suggest that additional $\mathrm{OH}$ exposure unlocks new generations of chemistry that contribute to SOA formation. These observations are consistent with the relatively rapid formation of highly oxidized, lowvolatility SOA during the course of the experiment. 


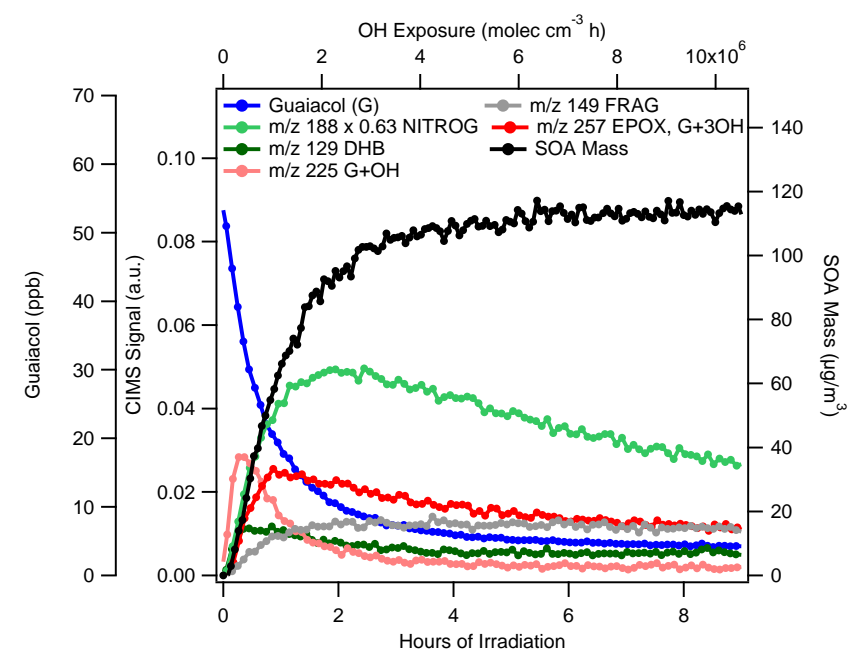

Fig. A1. Guaiacol high- $\mathrm{NO}_{\mathrm{x}}$ gas-phase and particle-phase development.

\section{A2 Phenol high-NO $\mathrm{N}_{\mathrm{x}}$ chemistry}

Olariu et al. (2002) measured yields of 0.8 catechol $(1,2-$ dihydroxybenzene), 0.037 1,4-benzoquinone, and 0.0582 nitrophenol using Fourier transform infrared (FT-IR) absorption spectroscopy for phenol photooxidation in the presence of $\mathrm{NO}_{\mathrm{x}}$. The CIMS traces in this study are consistent with these products. We find the major signals in the CIMS at $\mathrm{m} / \mathrm{z}$ 129 (dihydroxybenzene) and $\mathrm{m} / \mathrm{z} 158$ (nitrophenol). There is some signal at $\mathrm{m} / \mathrm{z}, 211$ and $\mathrm{m} / \mathrm{z}, 174$ indicating that trihydroxybenzene and its nitro-product are present in small amounts. However, according to the kinetic data and yield comparisons for nitrophenol presented in Berndt and Boge (2003), it is likely that nitro-product formation is favored from reaction of phenoxy radicals with $\mathrm{NO}_{2}$ due to sufficiently high $\mathrm{NO}_{2}$ concentrations in these experiments (max. $\mathrm{NO}_{2} \sim 500 \mathrm{ppb}$ ). The relative signals in the CIMS indicated such a bias existed. Berndt and Boge (2003) point out that for atmospheric conditions with $\mathrm{NO}_{2}$ of approximately $20 \mathrm{ppb}$, it is probable that phenoxy radicals also react with $\mathrm{O}_{3}$ and other species. In negative mode operation, the CIMS is not sensitive to quinone products, however, there are masses in positive mode operation at $\mathrm{m} / \mathrm{z}, 109$ and 127 that may be the $[\mathrm{M}+1]^{+}$and $[\mathrm{M}+19]^{+}$ions of benzoquinone. The set of $\mathrm{C}_{6}$ ring-opened acids as proposed in Fig. 3 for low- $\mathrm{NO}_{\mathrm{x}}$ conditions is not prevalent under high- $\mathrm{NO}_{\mathrm{x}}$ conditions, except for the acid at $m / 2$ 145. An alkoxy radical generated from $\mathrm{RO}_{2}+$ $\mathrm{NO}$ results in the same acid $\left(\mathrm{C}_{6} \mathrm{H}_{6} \mathrm{O}_{3}\right)$. Signals for proposed acidic fragments at $m / z, 185$ and $m / z 201$ in the low- $\mathrm{NO}_{\mathrm{X}}$ case are also present under high- $\mathrm{NO}_{\mathrm{x}}$ conditions.

\section{A3 Guaiacol high-NO $\mathrm{x}_{\mathrm{x}}$ chemistry}

During experiments with HONO injection, the majority of guaiacol is rapidly converted to nitroguaiacol $\left(\mathrm{C}_{7} \mathrm{H}_{7} \mathrm{NO}_{4}\right)$
Table A2. SOA products observed in UPLC/(-)ESI-ToFMS offline filter analysis for the guaiacol high- $\mathrm{NO}_{\mathrm{x}}$ system.

\begin{tabular}{cccc}
\hline$[\mathrm{M}-\mathrm{H}]^{-}$ & Meas. Mass & $\begin{array}{c}\text { Suggested Chemical } \\
\text { Formula }(\mathrm{M})\end{array}$ & $\begin{array}{c}\text { Error* } \\
(\mathrm{mDa})\end{array}$ \\
\hline 154 & 154.0121 & $\mathrm{C}_{6} \mathrm{H}_{5} \mathrm{NO}_{4}$ & -1.9 \\
170 & 170.0069 & $\mathrm{C}_{6} \mathrm{H}_{5} \mathrm{NO}_{5}$ & -2 \\
186 & 186.0023 & $\mathrm{C}_{6} \mathrm{H}_{5} \mathrm{NO}_{6}$ & -1.6 \\
199 & 198.9965 & $\mathrm{C}_{6} \mathrm{H}_{4} \mathrm{~N}_{2} \mathrm{O}_{6}$ & -2.6 \\
200 & 200.0182 & $\mathrm{C}_{7} \mathrm{H}_{7} \mathrm{NO}_{6}$ & -1.3 \\
184 & 184.0229 & $\mathrm{C}_{7} \mathrm{H}_{7} \mathrm{NO}_{5}$ & -1.7 \\
\hline
\end{tabular}
* The error in the accurate mass measurements is the difference between the
theoretical mass of the suggested molecular formulae and the measured mass
of the ion.

monitored at $m / z$ 188, NITROG, in Fig. A1. Production of dihydroxybenzene and the $\mathrm{OH}$ adducts still occurs as seen in the low- $\mathrm{NO}_{\mathrm{x}}$ case, as well as their nitro analogs in the high$\mathrm{NO}_{\mathrm{x}}$ case. However, the nitro $\mathrm{OH}$ adducts are formed in minor amounts. The hydroperoxide channel is negligible as expected. However, the presence of $\mathrm{NO}_{\mathrm{x}}$ seems to favor the production of many nitrogen-containing fragments since there is a prevalence of even-numbered $m / z$ 's $<200$ in the CIMS spectra. Some of the identifications of these ions remains elusive. Additional even-numbered fragments are present, but of low signal to noise.

Table A2 lists a few of the most prevalent particle-phase products (from highest to lowest peak area). The filter data show that dihydroxybenzene with a nitro group $\left(\mathrm{C}_{6} \mathrm{H}_{5} \mathrm{NO}_{4}\right)$ is incorporated into the particle phase as well as up to two more oxygens $\left(\mathrm{C}_{6} \mathrm{H}_{5} \mathrm{NO}_{5}, \mathrm{C}_{6} \mathrm{H}_{5} \mathrm{NO}_{6}\right)$. The formation of these essentially non-volatile products and rapid incorporation into the particle phase is consistent with the lack of CIMS observations for such oxygenated compounds in the guaiacol high- $\mathrm{NO}_{\mathrm{x}}$ system. The presence of particle-phase $\mathrm{C}_{6} \mathrm{H}_{4} \mathrm{~N}_{2} \mathrm{O}_{6}$ suggests that this product may be a $\mathrm{C}_{6}$ ring fragment that undergoes additional oxidation. The $\mathrm{C}_{7}$ products are consistent with the minimally detected gas-phase formation of nitroguaiacol $\mathrm{OH}$ adducts, also supporting rapid incorporation into the particle phase. One thing to note is that while the filter data suggest that the majority of particlephase products are nitrogen containing, this may be partially biased by sensitivity of the technique for measuring such compounds. The AMS bulk analyses show that the guaiacol system $\mathrm{N}: \mathrm{C}$ ratio is only 0.04 which does not match the average $\mathrm{N}: \mathrm{C}$ represented by the products in Table A2. However, the AMS $\mathrm{N}: \mathrm{C}$ ratio may also be biased low by uncertainties introduced if many of these species are organonitrates (Farmer et al., 2010).

\section{A4 Syringol high- $\mathrm{NO}_{\mathrm{x}}$ chemistry}

High- $\mathrm{NO}_{\mathrm{x}}$ syringol photooxidation is dominated primarily by $\mathrm{m} / \mathrm{z}, 275$ again, and fragments (Fig. A2). The ion at $\mathrm{m} / \mathrm{z}$ 203 is likely a volatile fragment and was also prominent 


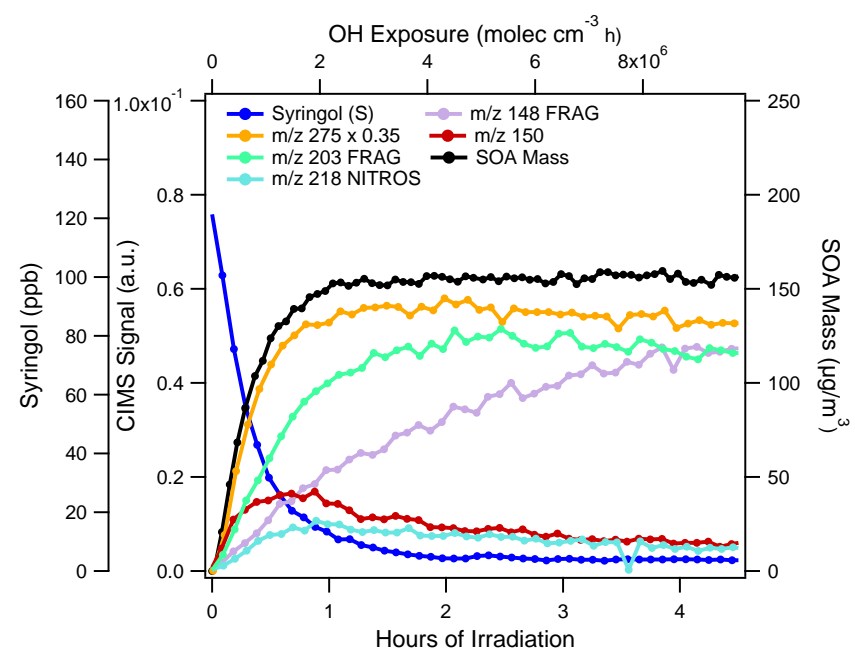

Fig. A2. Syringol high- $\mathrm{NO}_{\mathrm{x}}$ gas-phase and particle-phase development.

in the guaiacol high- $\mathrm{NO}_{\mathrm{x}}$ system. Nitrosyringol is a small contribution at $m / z, 218$ (NITROS) and unidentified $\mathrm{m} / z, 150$ grows in and reacts quickly in a similar manner. An ion at $\mathrm{m} / \mathrm{z} 148$ growing in over time indicates the conversion of some of these initial nitro-containing products to nitrogencontaining fragments. This may also explain why the aerosol yields in the high- $\mathrm{NO}_{\mathrm{x}}$ case appear to be slightly lower than those in the low- $\mathrm{NO}_{\mathrm{x}}$ case. Particle-phase analyses and structure identification would be necessary to further understand if the particle phase consists mostly of $<\mathrm{C}_{8}$ species.

While in the low- $\mathrm{NO}_{\mathrm{x}}$ case one is able to distinguish some conversion of syringol to guaiacol and hydroxy guaiacol, the presence of $\mathrm{NO}_{\mathrm{x}}$ seems to rapidly lead to incorporation of a nitro group. Nitroguaiacol species are minor species in this system. The SOA forms quickly in this case and could be due to rapid incorporation of the nitroguaiacol and nitrosyringol products into the particle phase.

\section{A5 Chemical differences between high-NO $\mathrm{O}_{\mathrm{x}}$ and low-NO $\mathrm{N}_{\mathrm{x}}$ chemistry}

In the case of guaiacol and syringol, product identifications are generally analogous for the low and high- $\mathrm{NO}_{\mathrm{x}}$ cases, except that more nitrogen-containing species are present in the high- $\mathrm{NO}_{\mathrm{x}}$ case. Both cases result in fragments that are often acidic and have the potential to become further oxidized. It is likely that these highly oxidized fragments are incorporated into the particle phase as observed in the filter analyses for the guaiacol low- $\mathrm{NO}_{\mathrm{x}}$ system. If alkylperoxy radicals preferentially decompose to regenerate $\mathrm{OH}$ via novel $\mathrm{RO}_{2}+\mathrm{HO}_{2}$ pathways as observed from aromatic peroxy radicals (Birdsall et al., 2010) or to generate carbonyls via novel rearrangements of ether peroxy radicals (Orlando and Tyndall, 2012), this further makes the product distributions less distinct from alkoxy radical pathways in high- $\mathrm{NO}_{\mathrm{x}}$ chemistry.
In the guaiacol system, the acidic fragment traces in the CIMS have the same time profile as the SOA growth in the low- $\mathrm{NO}_{\mathrm{x}}$ case. Under high- $\mathrm{NO}_{\mathrm{x}}$ conditions, the SOA growth does not follow the same time profile as any of the major gas-phase products. This suggests that under the experimental conditions of OH exposure, the SOA under low- $\mathrm{NO}_{\mathrm{x}}$ conditions may be dominated by production of more highly oxidized and lower volatility products than under high- $\mathrm{NO}_{\mathrm{x}}$ conditions. The major difference between SOA formation in the low- and high- $\mathrm{NO}_{\mathrm{x}}$ conditions may be attributed to the nitrogroup incorporation into the ring. Comparison of the predominant first-generation product nitroguaiacol $\left(\mathrm{C}_{7} \mathrm{H}_{7} \mathrm{NO}_{4}\right)$ under high- $\mathrm{NO}_{\mathrm{x}}$ conditions to any of the $\mathrm{C}_{7}$-retaining first generation products (typically $\mathrm{O}>5$ ) under low- $\mathrm{NO}_{x}$ conditions demonstrates that the low- $\mathrm{NO}_{\mathrm{x}}$ case begins with relatively lower vapor pressure products. Though we did not observe appreciable evidence of gas-phase hydroperoxides in the low- $\mathrm{NO}_{\mathrm{x}}$ case, they may be rapidly incorporated into the particle phase. With continued $\mathrm{OH}$ addition in the low- $\mathrm{NO}_{\mathrm{x}}$ case and competing nitro-group addition in the high- $\mathrm{NO}_{\mathrm{x}}$ case, the volatilities resulting from addition of the hydroxyl and nitro groups can rival one another. Though, hydroxyl groups will lead to a vapor pressure lowering more than that associated with nitro groups. In addition, the nitroguaiacol fate is predominantly gas-phase reaction with $\mathrm{OH}$, as it does not have sufficient oxygens as represented by the majority of products observed in the filter data $\left(>\mathrm{O}_{4}\right)$. Owing to the lower $\mathrm{OH}$ reactivity of the molecule containing a nitro group as compared to the comparable molecule containing a hydroxyl group (Kwok and Atkinson, 1995), this also suggests that more $\mathrm{OH}$ is necessary in the high- $\mathrm{NO}_{\mathrm{x}}$ case to attain further gas-phase development to more highly oxidized species. For example, while $\mathrm{RO}_{2}+\mathrm{NO}$ chemistry generally leads to fragmentation, there is a tendency for at least $\mathrm{C}_{6}$ highly oxygenated nitrogen containing species to be retained. This could be due to lack of continued $\mathrm{OH}$ exposure. It is also possible that the $\mathrm{C}_{6}$ species are derived from the dihydroxybenzene route in guaiacol photooxidation, rather than $\mathrm{RO}_{2}+$ NO induced carbon-carbon cleavage.

In general, the CIMS spectra indicate there is greater signal at the fragmented acidic species compared to the ring retaining species, and these fragment traces tend to have a time profile that is in equilibrium with SOA growth. Though there are distinct nitrogen-containing products in the high$\mathrm{NO}_{\mathrm{x}}$ case, it is again the fragments (many at the same $\mathrm{m} / \mathrm{z}$ as the low- $\mathrm{NO}_{x}$ case) and some nitrogen-containing fragment traces that seem to be in equilibrium with the particle phase. Thus, while nitrogen incorporation may occur early on in the high- $\mathrm{NO}_{\mathrm{x}}$ cases, there is still a degree of oxygenation required for these species to be incorporated in the particle phase. This is consistent with the observation of several aerosol species in the guaiacol high- $\mathrm{NO}_{\mathrm{x}}$ system that have chemical formulae with one nitrogen, but $>3$ oxygens (more than guaiacol itself). AMS elemental analyses of SOA from these systems as reported in Chhabra et al. (2011) suggest 
that the majority of oxygenation is derived from organic acid functionalities under both $\mathrm{NO}_{\mathrm{x}}$ conditions, ranging 61-77\% for phenol and guaiacol and $54-59 \%$ for syringol. There is a $<7 \%$ contribution from organic nitrate groups under high- $\mathrm{NO}_{\mathrm{x}}$ conditions. The relatively lower contribution of oxygenation from organic acid groups in the syringol system compared to phenol and guaiacol may partially explain why the syringol SOA yield is also lower. SOA formation from these compounds may be dominated by acidic species that result from ring-opening pathways, so prevention of this pathway (as evidenced by the presence of $m / z 275$ under both conditions of $\mathrm{NO}_{\mathrm{x}}$ ) in the case of syringol would hinder SOA formation.

Acknowledgements. This work was supported by the US Department of Energy grants DE-FG02-05ER63983 and DE-SC 0006626 and US Environmental Protection Agency (EPA) STAR Research Agreement No. RD-833749.

Edited by: M. Ammann

\section{References}

Aihara, K., Urano, Y., Higuchi, T., and Hirobe, M.: Mechanistic studies of selective catechol formation from o-methoxyphenols using a copper(II) ascorbic-acid dioxygen system, J. Chem. Soc. Perk. T., 2, 2165-2170, doi:10.1039/p29930002165, 1993.

Aiken, A. C., DeCarlo, P. F., and Jimenez, J. L.: Elemental analysis of organic species with electron ionization high-resolution mass spectrometry, Anal. Chem., 79, 8350-8358, 2007.

Aiken, A. C., DeCarlo, P. F., Kroll, J. H., Worsnop, D. R., Huffman, J. A., Docherty, K. S., Ulbrich, I. M., Mohr, C., Kimmel, J. R., Sueper, D., Sun, Y., Zhang, Q., Trimborn, A., Northway, M., Ziemann, P. J., Canagaratna, M. R., Onasch, T. B., Alfarra, M. R., Prevot, A. S. H., Dommen, J., Duplissy, J., Metzger, A., Baltensperger, U., and Jimenez, J. L.: O/C and OM/OC ratios of primary, secondary, and ambient organic aerosols with high-resolution time-of-flight aerosol mass spectrometry, Environ. Sci. Technol., 42, 4478-4485, 2008.

Akagi, S. K., Craven, J. S., Taylor, J. W., McMeeking, G. R., Yokelson, R. J., Burling, I. R., Urbanski, S. P., Wold, C. E., Seinfeld, J. H., Coe, H., Alvarado, M. J., and Weise, D. R.: Evolution of trace gases and particles emitted by a chaparral fire in California, Atmos. Chem. Phys., 12, 1397-1421, doi:10.5194/acp-12-13972012, 2012.

Allan, J. D., Delia, A. E., Coe, H., Bower, K. N., Alfarra, M. R., Jimenez, J. L., Middlebrook, A. M., Drewnick, F., Onasch, T. B., Canagaratna, M. R., Jayne, J. T., and Worsnop, D. R.: A generalised method for the extraction of chemically resolved mass spectra from Aerodyne aerosol mass spectrometer data, J. Aerosol Sci., 35, 909-922, 2004.

Ammann, M., Rossler, E., Strekowski, R., and George, C.: Nitrogen dioxide multiphase chemistry: Uptake kinetics on aqueous solutions containing phenolic compounds, Phys. Chem. Chem. Phys., 7, 2513-2518, 2005.

Aschmann, S. M., Arey, J., and Atkinson, R.: Extent of Hatom abstraction from $\mathrm{OH}$ plus p-cymene and upper lim- its to the formation of cresols from $\mathrm{OH}$ plus m-xylene and $\mathrm{OH}$ plus p-cymene, Atmos. Environ., 44, 3970-3975, doi:10.1016/j.atmosenv.2010.06.059, 2010.

Atkinson, R., Aschmann, S. M., and Arey, J.: Reactions of hydroxyl and nitrogen trioxide radicals with phenol, cresols, and 2-nitrophenol at $296+-2$ K, Environ. Sci. Technol., 26, 13971403, doi:10.1021/es00031a018, 1992.

Bahreini, R., Keywood, M. D., Ng, N. L., Varutbangkul, V., Gao, S., Flagan, R. C., Seinfeld, J. H., Worsnop, D. R., and Jimenez, J. L.: Measurements of secondary organic aerosol from oxidation of cycloalkenes, terpenes, and m-xylene using an Aerodyne aerosol mass spectrometer, Environ. Sci. Technol., 39, 5674-5688, 2005.

Berndt, T. and Boge, O.: Gas-phase reaction of $\mathrm{OH}$ radicals with phenol, Phys. Chem. Chem. Phys., 5, 342-350, doi:10.1039/b208187c, 2003.

Berndt, T. and Boge, O.: Formation of phenol and carbonyls from the atmospheric reaction of $\mathrm{OH}$ radicals with benzene, Phys. Chem. Chem. Phys., 8, 1205-1214, doi:10.1039/B514148F, 2006.

Birdsall, A. W., Andreoni, J. F., and Elrod, M. J.: Investigation of the role of bicyclic peroxy radicals in the oxidation mechanism of toluene, J. Phys. Chem. A, 114, 10655-10663, doi:10.1021/jp105467e, 2010

Bloss, C., Wagner, V., Bonzanini, A., Jenkin, M. E., Wirtz, K., Martin-Reviejo, M., and Pilling, M. J.: Evaluation of detailed aromatic mechanisms (MCMv3 and MCMv3.1) against environmental chamber data, Atmos. Chem. Phys., 5, 623-639, doi:10.5194/acp-5-623-2005, 2005.

Bond, T. C., Streets, D. G., Yarber, K. F., Nelson, S. M., Woo, J. H., and Klimont, Z.: A technology-based global inventory of black and organic carbon emissions from combustion, J. Geophys. Res.-Atmos., 109, D14203, doi:10.1029/2003JD003697, 2004.

Calvert, J. G., Atkinson, R., Becker, K. H., Kamens, R. M., Seinfeld, J. H., Wallington, T. J., and Yarwood, G.: The Mechanisms of Atmospheric Oxidation of Aromatic Hydrocarbons, Oxford University Press, Inc, New York, USA, 2002.

Chan, A. W. H., Kroll, J. H., Ng, N. L., and Seinfeld, J. H.: Kinetic modeling of secondary organic aerosol formation: effects of particle- and gas-phase reactions of semivolatile products, Atmos. Chem. Phys., 7, 4135-4147, doi:10.5194/acp-7-4135-2007, 2007.

Chhabra, P. S., Ng, N. L., Canagaratna, M. R., Corrigan, A. L., Russell, L. M., Worsnop, D. R., Flagan, R. C., and Seinfeld, J. H.: Elemental composition and oxidation of chamber organic aerosol, Atmos. Chem. Phys., 11, 8827-8845, doi:10.5194/acp-11-88272011, 2011.

Cocker, D. R., Flagan, R. C., and Seinfeld, J. H.: State-of-the-art chamber facility for studying atmospheric aerosol chemistry, Environ. Sci. Technol., 35, 2594-2601, 2001.

Coeur-Tourneur, C., Tomas, A., Guilloteau, A., Henry, F., Ledoux, F., Visez, N., Riffault, V., Wenger, J. C., and Bedjanian, Y.: Aerosol formation yields from the reaction of catechol with ozone, Atmos. Environ., 43, 2360-2365, doi:10.1016/j.atmosenv.2008.12.054, 2009.

Coeur-Tourneur, C., Cassez, A., and Wenger, J. C.: Rate coefficients for the gas-phase reaction of hydroxyl radicals with 2-Methoxyphenol (guaiacol) and related compounds, J. Phys. Chem. A, 114, 11645-11650, doi:10.1021/jp1071023, 2010. 
Collins, E., Sidebottom, H., Wenger, J., Calvé, S. L., Mellouki, A., LeBras, G., Villenave, E., and Wirtz, K.: The influence of reaction conditions on the photooxidation of diisopropyl ether, J. Photoch. Photobio. A, 176, 86-97, doi:10.1016/j.jphotochem.2005.09.004, 2005.

DeCarlo, P. F., Kimmel, J. R., Trimborn, A., Northway, M. J., Jayne, J. T., Aiken, A. C., Gonin, M., Fuhrer, K., Horvath, T., Docherty, K. S., Worsnop, D. R., and Jimenez, J. L.: Field-deployable, high-resolution, time-of-flight aerosol mass spectrometer, Anal. Chem., 78, 8281-8289, 2006.

Dills, R. L., Zhu, X. Q., and Kalman, D. A.: Measurement of urinary methoxyphenols and their use for biological monitoring of wood smoke exposure, Environ. Res., 85, 145-158, 2001.

U.S. EPA.: EPI Suite v4.11, http://www.epa.gov/opptintr/exposure/ pubs/episuitedl.htm, 2012.

Farmer, D. K., Matsunaga, A., Docherty, K. S., Surratt, J. D., Seinfeld, J. H., Ziemann, P. J., and Jimenez, J. L.: Response of an aerosol mass spectrometer to organonitrates and organosulfates and implications for atmospheric chemistry, P. Natl. Acad. Sci. USA, 107, 6670-6675, doi:10.1073/pnas.0912340107, 2010.

Fine, P. M., Cass, G. R., and Simoneit, B. R. T.: Chemical characterization of fine particle emissions from fireplace combustion of woods grown in the northeastern United States, Environ. Sci. Technol., 35, 2665-2675, 2001.

Gomez, N., Henon, E., Bohr, F., and Devolder, P.: Rate constants for the reactions of $\mathrm{CH} 3 \mathrm{O}$ with cyclohexane, cyclohexene, and 1,4cyclohexadiene: Variable temperature experiments and theoretical comparison of addition and H-abstraction channels, J. Phys. Chem. A, 105, 11204-11211, doi:10.1021/jp010204h, 2001.

Hawthorne, S. B., Krieger, M. S., Miller, D. J., and Mathiason, M. B.: Collection and quantitation of methoxylated phenol tracers for atmospheric-pollution from residential wood stoves, Environ. Sci. Technol., 23, 470-475, 1989.

Hawthorne, S. B., Miller, D. J., Langenfeld, J. J., and Krieger, M. S.: PM-10 high-volume collection and quantification of semivolatile and nonvolatile phenols, methoxylated phenols, alkanes, and polycyclic aromatic-hydrocarbons from winter urban air and their relationship to wood smoke emmisions, Environ. Sci. Technol., 26, 2251-2262, 1992.

Huey, L. G., Villalta, P. W., Dunlea, E. J., Hanson, D. R., and Howard, C. J.: Reactions of CF3O- with atmospheric trace gases, J. Phys. Chem., 100, 190-194, 1996.

Iinuma, Y., Böge, O., Gräfe, R., and Herrmann, H.: MethylNitrocatechols: Atmospheric tracer compounds for biomass burning secondary organic aerosols, Environ. Sci. Technol., 44, 8453-8459, doi:10.1021/es102938a, 2010.

Ito, A. and Penner, J. E.: Historical emissions of carbonaceous aerosols from biomass and fossil fuel burning for the period 1870-2000, Global Biogeochem. Cy., 19, GB2028, doi:10.1029/2004GB002374, 2005.

Johnson, D., Jenkin, M., Wirtz, K., and Martin-Reviejo, M.: Simulating the formation of secondary organic aerosol from the photooxidation of aromatic hydrocarbons, Environ. Chem., 2, 35-48, doi:10.1071/EN04079, 2005.

Justesen, U.: Collision-induced fragmentation of deprotonated methoxylated flavonoids, obtained by electrospray ionization mass spectrometry, J. Mass Spectrom., 36, 169-178, doi:10.1002/jms.118, 2001.
Kautzman, K. E., Surratt, J. D., Chan, M. N., Chan, A. W. H., Hersey, S. P., Chhabra, P. S., Dalleska, N. F., Wennberg, P. O., Flagan, R. C., and Seinfeld, J. H.: Chemical composition of gasand aerosol-phase products from the photooxidation of naphthalene, J. Phys. Chem. A, 114, 913-934, 2010.

Keywood, M. D., Varutbangkul, V., Bahreini, R., Flagan, R. C., and Seinfeld, J. H.: Secondary organic aerosol formation from the ozonolysis of cycloalkenes and related compounds, Environ. Sci. Technol., 38, 4157-4164, 2004.

Klotz, B., Volkamer, R., Hurley, M., Andersen, M., Nielsen, O., Barnes, I., Imamura, T., Wirtz, K., Becker, K., Platt, U., Wallington, T., and Washida, N.: OH-initiated oxidation of benzene Part II. influence of elevated $\mathrm{NO}_{\mathrm{x}}$ concentrations, Phys. Chem. Chem. Phys., 4, 4399-4411, doi:10.1039/b204398j, 2002.

Koch, R., Knispel, R., Elend, M., Siese, M., and Zetzsch, C.: Consecutive reactions of aromatic-OH adducts with $\mathrm{NO}, \mathrm{NO}_{2}$ and $\mathrm{O}_{2}$ : benzene, naphthalene, toluene, $\mathrm{m}$ - and p-xylene, hexamethylbenzene, phenol, m-cresol and aniline, Atmos. Chem. Phys., 7, 2057-2071, doi:10.5194/acp-7-2057-2007, 2007.

Kroll, J. H., Ng, N. L., Murphy, S. M., Flagan, R. C., and Seinfeld, J. H.: Secondary organic aerosol formation from isoprene photooxidation, Environ. Sci. Technol., 40, 1869-1877, doi:10.1021/es0524301, 2006.

Kroll, J. H., Donahue, N. M., Jimenez, J. L., Kessler, S. H., Canagaratna, M. R., Wilson, K. R., Altieri, K. E., Mazzoleni, L. R., Wozniak, A. S., Bluhm, H., Mysak, E. R., Smith, J. D., Kolb, C. E., and Worsnop, D. R.: Carbon oxidation state as a metric for describing the chemistry of atmospheric organic aerosol, Nat. Chem., 3, 133-139, doi:10.1038/nchem.948, 2011.

Kwok, E. S. and Atkinson, R.: Estimation of hydroxyl radical reaction rate constants for gas-phase organic compounds using a structure-reactivity relationship: An update, Atmos. Environ., 29, 1685-1695, doi:10.1016/1352-2310(95)00069-B, 1995.

Lauraguais, A., Coeur-Tourneur, C., Cassez, A., and Seydi, A.: Rate constant and secondary organic aerosol yields for the gas-phase reaction of hydroxyl radicals with syringol (2,6-dimethoxyphenol), Atmos. Environ., 55, 43-48, doi:10.1016/j.atmosenv.2012.02.027, 2012.

Luo, Y. R.: Comprehensive Handbook of Chemical Bond Energies, CRC Press, Boca Raton, FL, 2007.

Naeher, L. P., Brauer, M., Lipsett, M., Zelikoff, J. T., Simpson, C. D., Koenig, J. Q., and Smith, K. R.: Woodsmoke health effects: A review, Inhal. Toxicol., 19, 67-106, 2007.

Nakao, S., Clark, C., Tang, P., Sato, K., and Cocker III, D.: Secondary organic aerosol formation from phenolic compounds in the absence of $\mathrm{NO}_{\mathrm{x}}$, Atmos. Chem. Phys., 11, 10649-10660, doi:10.5194/acp-11-10649-2011, 2011.

Ng, N. L., Kroll, J. H., Keywood, M. D., Bahreini, R., Varutbangkul, V., Flagan, R. C., Seinfeld, J. H., Lee, A., and Goldstein, A. H.: Contribution of first- versus second-generation products to secondary organic aerosols formed in the oxidation of biogenic hydrocarbons, Environ. Sci. Technol., 40, 2283-2297, 2006.

Ng, N. L., Chhabra, P. S., Chan, A. W. H., Surratt, J. D., Kroll, J. H., Kwan, A. J., McCabe, D. C., Wennberg, P. O., Sorooshian, A., Murphy, S. M., Dalleska, N. F., Flagan, R. C., and Seinfeld, J. H.: Effect of $\mathrm{NO}_{\mathrm{x}}$ level on secondary organic aerosol (SOA) formation from the photooxidation of terpenes, Atmos. Chem. Phys., 7, 5159-5174, doi:10.5194/acp-7-5159-2007, 2007. 
Nieto-Gligorovski, L., Net, S., Gligorovski, S., Zetzsch, C., Jammoul, A., D'Anna, B., and George, C.: Interactions of ozone with organic surface films in the presence of simulated sunlight: impact on wettability of aerosols, Phys. Chem. Chem. Phys., 10, 2964-2971, doi:10.1039/B717993F, 2008.

Nishino, N., Atkinson, R., and Arey, J.: Formation of nitro products from the gas-phase $\mathrm{OH}$ radical-initiated reactions of toluene, naphthalene, and biphenyl: effect of $\mathrm{NO}_{2}$ concentration, Environ. Sci. Technol., 42, 9203-9209, doi:10.1021/es802046m, 2008.

Noda, J., Volkamer, R., and Molina, M. J.: Dealkylation of Alkylbenzenes: A Significant Pathway in the Toluene, o-, m-, pXylene + OH Reaction, J. Phys. Chem. A, 113, 9658-9666, doi:10.1021/jp901529k, 2009.

Ofner, J., Kruger, H.-U., and Zetzsch, C.: Time Resolved Infrared Spectroscopy of Formation and Processing of Secondary Organic Aerosol, Z. Phys. Chem., 224, 1171-1183, doi:10.1524/zpch.2010.6146, 2010.

Ofner, J., Krüger, H.-U., Grothe, H., Schmitt-Kopplin, P., Whitmore, K., and Zetzsch, C.: Physico-chemical characterization of SOA derived from catechol and guaiacol - a model substance for the aromatic fraction of atmospheric HULIS, Atmos. Chem. Phys., 11, 1-15, doi:10.5194/acp-11-1-2011, 2011.

Olariu, R. I., Tomas, A., Barnes, I., Bejan, I., Becker, K. H., and Wirtz, K.: Atmospheric Ozone Degradation Reaction of 1,2Dihydroxybenezene, EUPHORE 4th Report 2001, Tech. rep., Complied and Produced by Institute of Physical Chemistry, Bergische Universität Wuppertal, Germany, 2001.

Olariu, R. I., Klotz, B., Barnes, I., Becker, K. H., and Mocanu, R.: FTIR study of the ring-retaining products from the reaction of $\mathrm{OH}$ radicals with phenol, o-, m-, and p-cresol, Atmos. Environ., 36, 3685-3697, 2002.

Orlando, J. J. and Tyndall, G. S.: Laboratory studies of organic peroxy radical chemistry: an overview with emphasis on recent issues of atmospheric significance, Chem. Soc. Rev., 41, 62946317, doi:10.1039/c2cs35166h, 2012.

Pankow, J.: An absorption-model of gas-particle partitioning of organic-compounds in the atmosphere, Atmos. Environ., 28, 185-188, doi:10.1016/1352-2310(94)90093-0, 1994.

Pye, H. O. T. and Seinfeld, J. H.: A global perspective on aerosol from low-volatility organic compounds, Atmos. Chem. Phys., 10, 4377-4401, doi:10.5194/acp-10-4377-2010, 2010.

Raff, J. D. and Hites, R. A.: Gas-Phase Reactions of Brominated Diphenyl Ethers with OH Radicals, J. Phys. Chem. A, 110, 10783-10792, doi:10.1021/jp0630222, 2006.

Sander, S. P., Abbatt, J. P. D., Barker, J. R., Burkholder, J. B., Friedl, R. R., Golden, D. M., Huie, R. E., Kolb, C. E., Moortgat, G. K., Orkin, V. L., and Wine, P. H.: Chemical kinetics and photochemical data for use in atmospheric studies, Evaluation No. 17, JPL Publication 10-6, 2011, http://jpldataeval.jpl.nasa.gov, 2011.
Sato, K., Hatakeyama, S., and Imamura, T.: Secondary organic aerosol formation during the photooxidation of toluene: $\mathrm{NO}_{\mathrm{x}}$ dependence of chemical composition, J. Phys. Chem. A, 111, 9796-9808, doi:10.1021/jp071419f, 2007.

Schauer, J. J., Kleeman, M. J., Cass, G. R., and Simoneit, B. R. T.: Measurement of emissions from air pollution sources. 3. C-1-C29 organic compounds from fireplace combustion of wood, Environ. Sci. Technol., 35, 1716-1728, 2001.

Simpson, C. D. and Naeher, L. P.: Biological monitoring of woodsmoke exposure, Inhal. Toxicol., 22, 99-103, 2010.

St. Clair, J. M., McCabe, D. C., Crounse, J. D., Steiner, U., and Wennberg, P. O.: Chemical ionization tandem mass spectrometer for the in situ measurement of methyl hydrogen peroxide, Rev. Sci. Instrum., 81, 094102, doi:10.1063/1.3480552, 2010.

Sun, Y., Zhang, Q., Macdonald, A. M., Hayden, K., Li, S. M., Liggio, J., Liu, P. S. K., Anlauf, K. G., Leaitch, W. R., Steffen, A., Cubison, M., Worsnop, D. R., van Donkelaar, A., and Martin, R. V.: Size-resolved aerosol chemistry on Whistler Mountain, Canada with a high-resolution aerosol mass spectrometer during INTEX-B, Atmos. Chem. Phys., 9, 3095-3111, doi:10.5194/acp9-3095-2009, 2009.

Sun, Y. L., Zhang, Q., Anastasio, C., and Sun, J.: Insights into secondary organic aerosol formed via aqueous-phase reactions of phenolic compounds based on high resolution mass spectrometry, Atmos. Chem. Phys., 10, 4809-4822, doi:10.5194/acp-104809-2010, 2010.

Surratt, J. D., Gómez-González, Y., Chan, A. W. H., Vermeylen, R., Shahgholi, M., Kleindienst, T. E., Edney, E. O., Offenberg, J. H., Lewandowski, M., Jaoui, M., Maenhaut, W., Claeys, M., Flagan, R. C., and Seinfeld, J. H.: Organosulfate formation in biogenic secondary organic aerosol, J. Phys. Chem. A, 112, 8345-8378, 2008.

Tomas, A., Olariu, R. I., Barnes, I., and Becker, K. H.: Kinetics of the reaction of $\mathrm{O} 3$ with selected benzenediols, Int. J. Chem. Kinet., 35, 223-230, doi:10.1002/kin.10121, 2003.

Varfolomeev, M. A., Abaidullina, D. I., Solomonov, B. N., Verevkin, S. P., and Emel'yanenko, V. N.: Pairwise substitution effects, inter- and intramolecular hydrogen bonds in methoxyphenols and dimethoxybenzenes. thermochemistry, calorimetry, and first-principles calculations, J. Phys. Chem. B, 114, 16503-16516, doi:10.1021/jp108459r, 2010.

Veres, P., Roberts, J. M., Burling, I. R., Warneke, C., de Gouw, J., and Yokelson, R. J.: Measurements of gas-phase inorganic and organic acids from biomass fires by negative-ion proton-transfer chemical-ionization mass spectrometry, J. Geophys. Res., 115, D23302, doi:10.1029/2010JD014033, 2010. 